\title{
Lightning detection on Venus: a critical review
}

\author{
Ralph D. Lorenz(D)
}

\begin{abstract}
Claimed detections and nondetections of lightning and related electromagnetic emissions on Venus are qualitatively contradictory. Here, motivated by the commencement of observations by the Akatsuki spacecraft and by studies of future missions, we critically review spacecraft and ground-based observations of the past 40 years, in an attempt to reconcile the discordant reports with a minimal number of assumptions. These include invoking alternative interpretations of individual reports, guided by sensitivity thresholds, controls, and other objective benchmarks of observation integrity. The most compelling evidence is in fact the first, the very low frequency (VLF) radio emissions recorded beneath the clouds by all four of the Veneras 11-13 landers, and those data are re-examined closely, finding power-law amplitude characteristics and substantial differences between the different profiles. It is concluded that some kind of frequent electrical activity is supported by the preponderance of observations, but optical emissions are not consistent with terrestrial levels of activity. Venus' activity may, like Earth's, have strong temporal and/or spatial variability, which coupled with the relatively short accumulated observation time for optical measurements, can lead to qualitative discrepancies between observation reports. We note a number of previously unconsidered observations and outline some considerations for future observations.
\end{abstract}

Keywords: Venus, Lightning, Electromagnetic emission, Observation

\section{Introduction}

As our sister planet Venus attracts particular interest among solar system objects, it is further important to recognize that many Earth-sized planets now being detected around other stars are as likely to be "Venus-like" as they are "Earth-like." Lightning is an important process for several reasons (e.g. Rakov and Uman, 2003). First, it is a striking phenomenon in its own right. Second, it may serve as a diagnostic of other processes, such as volcanism or convection. Third, lightning may be important in atmospheric evolution and prebiotic evolution, notably in fixing nitrogen which is an essential element in living things but is generally chemically inaccessible. Finally, lightning may be a hazard for vehicles exploring a planetary atmosphere.

For these reasons, some effort has been devoted to detecting possible lightning on Venus, as indicated by the literature on the topic (Fig. 1)-major stimuli to the topic have been the Venera and Pioneer Venus results around

Correspondence: Ralph.Lorenz@jhuapl.edu

Johns Hopkins Applied Physics Laboratory, 11100 Johns Hopkins Road, Laurel, MD 20723, USA

(c) The Author(s). 2018 Open Access This article is distributed under the terms of the Creative Commons Attribution 4.0 International License (http://creativecommons.org/licenses/by/4.0/), which permits unrestricted use, distribution, and reproduction in any medium, provided you give appropriate credit to the original author(s) and the source, provide a link to the Creative Commons license, and indicate if changes were made.
1980 and the Venus Express results since 2007. Several previous surveys have reviewed planetary lightning generally (Desch et al. 2003; Yair 2012; Aplin 2013; Aplin and Fischer 2017). Reviews of Venus lightning specifically include Williams et al. 1983, Russell 1991, and Hunten 1995, and the two notably comprehensive reviews in the Arizona Press "Venus" books now two decades oldKsanfomality et al. 1983, Grebowsky et al. 1997. A comparatively recent Venus-specific review is given in Takahashi et al. (2008), who outlines the potential of new optical measurements on the Japanese Akatsuki Venus Climate Orbiter (Nakamura et al. 2007), which recently began operations at Venus after an extended journey (Nakamura et al. 2014). It may be noted that lightning has been repeatedly observed at Jupiter and Saturn and is not in dispute, and firm nondetections are established at Titan. At Venus, however, there are many superficially conflicting positive and negative reports. This review attempts to assess these reports critically, to develop scenarios that seem most probable in so far as they are consistent with the preponderance of observations. 


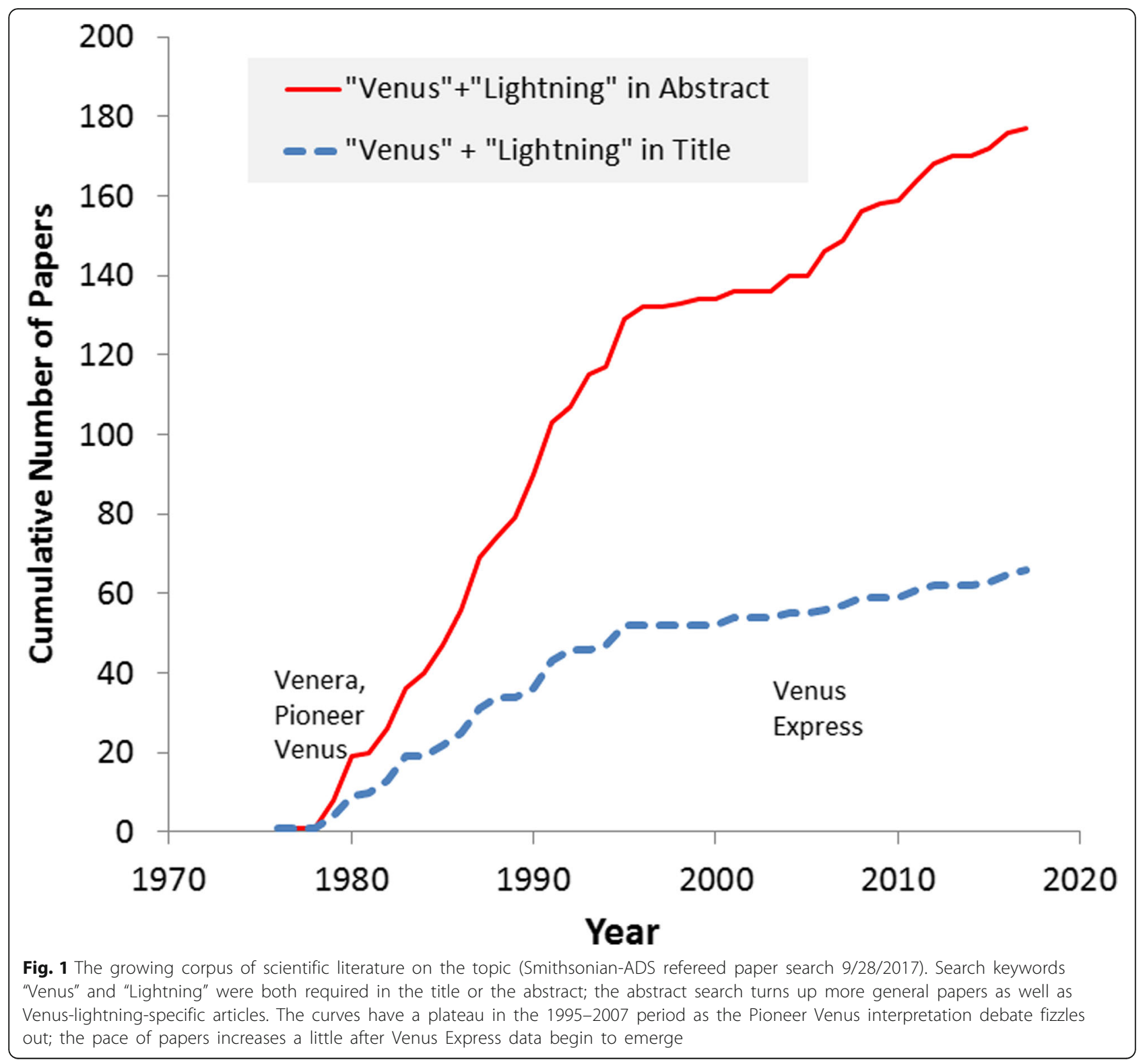

Broadly speaking, evidence for or against lightning on Venus may be classified in four general categories, which are shown schematically in Fig. 2, against the profiles of electron density in the ionosphere and the temperature of the lower atmosphere. The main cloud layer lies between about 50 and $75 \mathrm{~km}$ altitude.

A key point in this review is that it is futile to reconcile observations of claimed flash rates (or nondetection) without considering the robustness of the measurement (e.g., the quantification of false detection rate), the significance of the measurement (the area and duration of the observations), and the sensitivity (the magnitude of lightning discharge that would be detectable). Measurement sensitivity must also take into account the transfer of information from where the electrical discharge occurs to the location of the measurement system: this propagation may be inefficient or even impossible (e.g., blue light from the lower atmosphere is absorbed before reaching space), or may be highly variable as in the case of whistler-mode plasma waves. This information propagation is summarized in Fig. 3.

In this connection, it is interesting to consider that the detection footprints of the various techniques may have a counterintuitive trend-that higher-altitude surveys may sample a smaller area. Specifically, the extremely low frequency (ELF) $(\sim 100 \mathrm{~Hz})$ whistler-mode electromagnetic detections from orbit sample only an area connected to the spacecraft by appropriate ionospheric and magnetic field conditions and so may sense a range of only a couple of hundred kilometers from the subspacecraft 


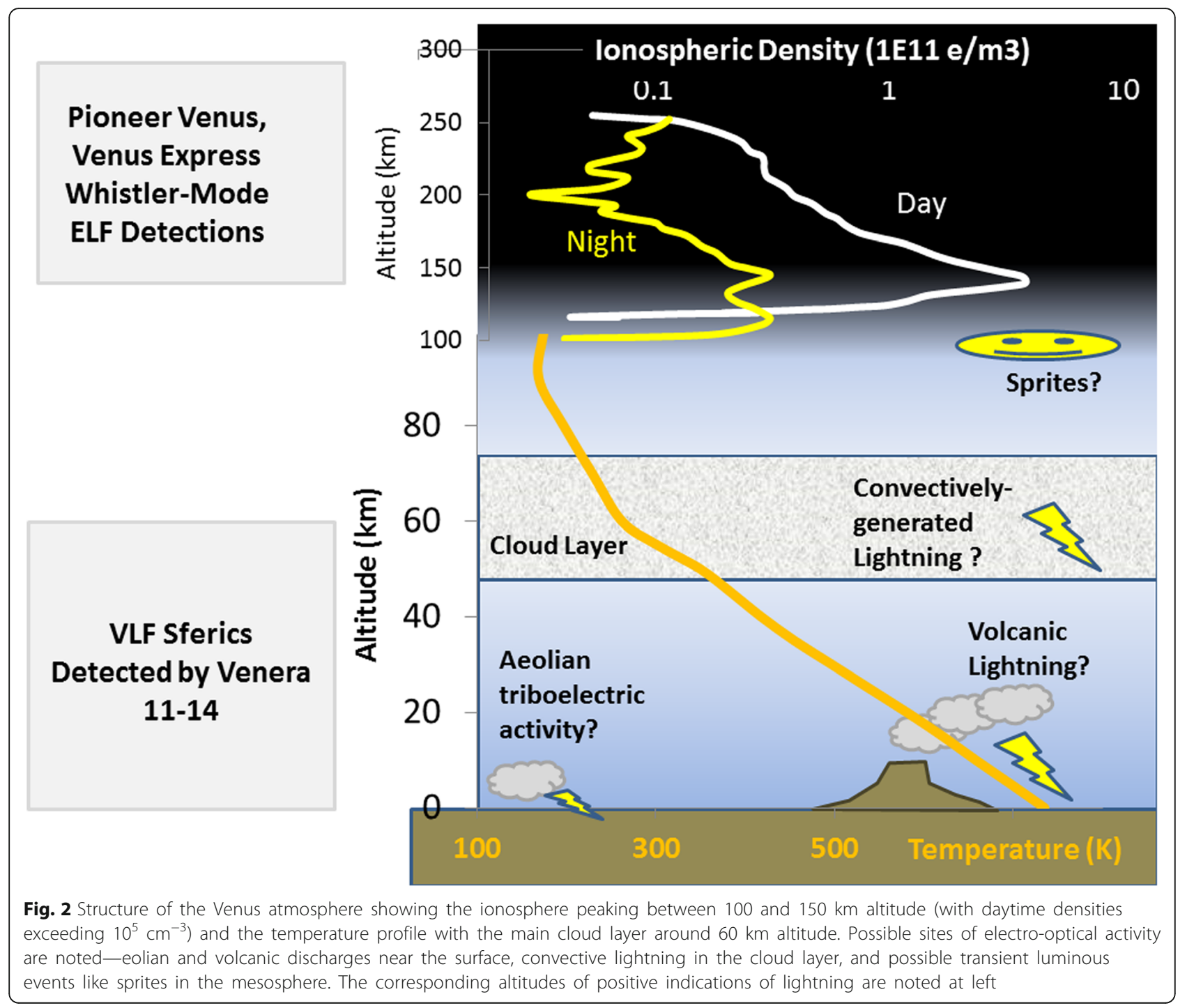

point. However, very low frequency (VLF) $(10-80 \mathrm{kHz})$ measurements by descent probes at low altitude may detect discharges at ranges of thousands of kilometers, due to ducted propagation by super-refraction in the lower atmosphere (Croft 1983) and/or by "skybounce"reflection from the ionosphere (e.g., Simões et al. 2008) see also discussion in Ksanfomality et al. (1983). Similar VLF detectors are now used routinely by networks on Earth to map and track lightning activity over planetaryscale distances (see, e.g., Wood and Inan 2002 or the World-Wide Lightning Location Network WWLLN at https://webflash.ess.washington.edu).

A key challenge is in the interpretation of electrical or magnetic signatures claimed to be whistler-mode emissions from lightning discharges. For the Pioneer Venus electric field data at least, several alternative explanations were offered, and much of the 1980s literature is cluttered with this debate. In part, a difficulty is that such observations somewhat transcend scientific disciplinary boundaries-atmospheric scientists are generally unfamiliar with plasma physics, and it is difficult for nonpartisan observers to gauge the robustness of different interpretations. What is clear, however, as we discuss later, is that such electromagnetic signatures are observed fairly consistently, and that lightning discharges are one possible origin.

A further point centers on the definition of "lightning." It is only in the last couple of decades (long after the Venus lightning debate began in earnest with Pioneer Venus) that a fuller range of optical phenomena associated with atmospheric electrical discharges has been recognized on Earth, namely sprites, elves, blue jets, and other emissions. Given the different environment on Venus, it seems highly likely that not only are lightning bolts (if they occur in the conventional sense) possibly different in character, but these other types of luminous events may be present and have 


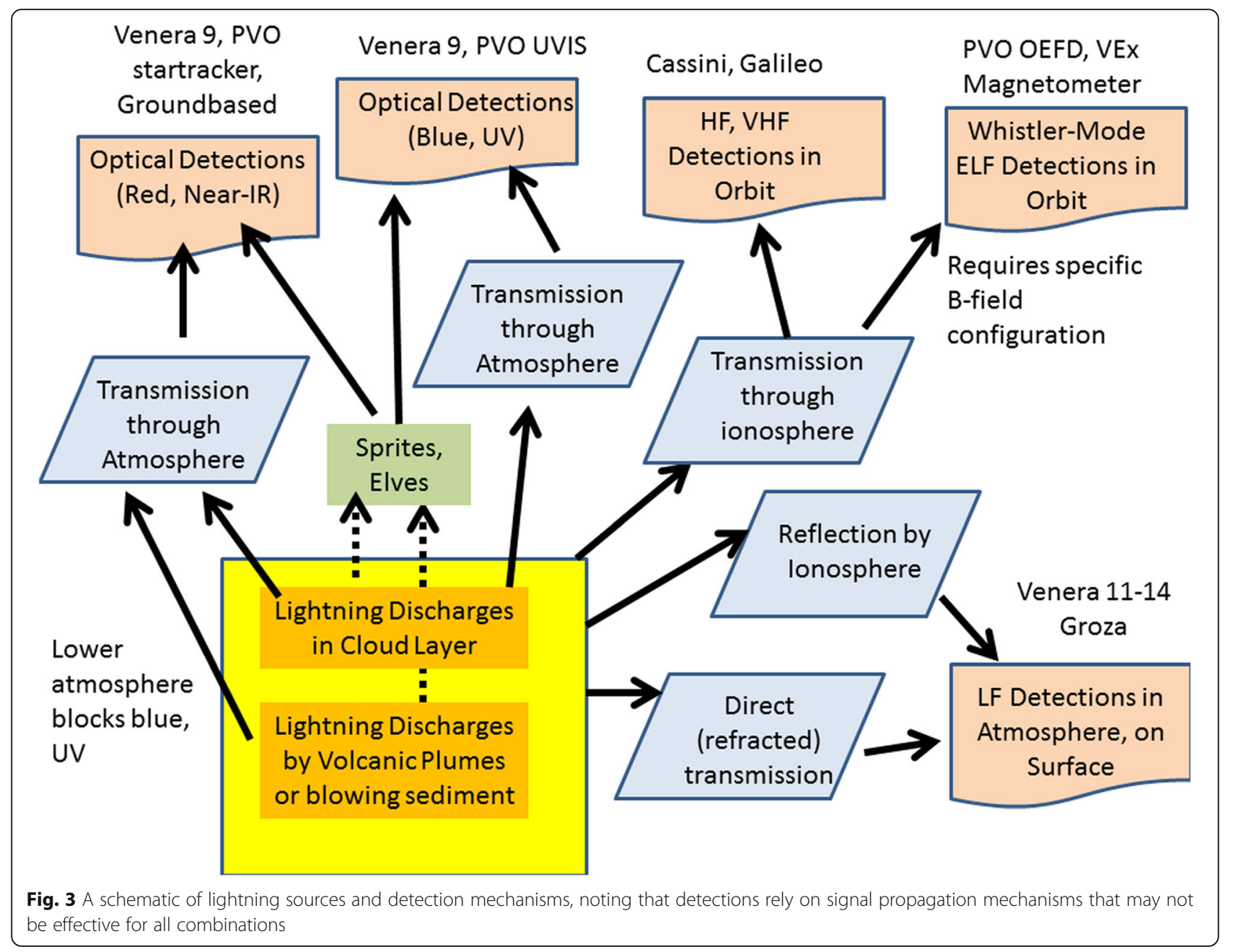

similar or different features compared with the Earth. For the purpose of this review, we consider "lightning" to be any optical emission associated with an electrical discharge, thus including ionosphere/mesosphere glows such as sprites as well as "conventional" lightning flashes.

It is interesting to lay out the development of Venus lightning studies in parallel (see Table 1) with progress in studying lightning at Earth. In fact, many significant terrestrial developments have been made since the first observations of possible lightning on Venus-notably the development of terrestrial networks of radio systems able to provide real-time and essentially global surveillance of lightning activity. Indeed, not only have these developed from national-scale systems such as the US National Lightning Detection Network NLDN to the global WWLLN, but even an amateur network exists ("Blitzortung.org") using simple VLF detectors linked to servers that locate strikes by time of arrival (see Fig. 4).

More pertinents, perhaps, from an analogy standpoint are the observations of terrestrial lightning from space. Vanguard III, only the 12th satellite to reach the orbit and only 2 years after Sputnik 1, carried a proton precession magnetometer, in which some VLF whistler-mode signals were detected (Cain et al. 1961). Orbital measurements of whistlers were more robustly observed and directly attributed to "fractional hop" whistler waves launched from near the sites of lightning discharges, by the Canadian satellite Alouette (Barrington and Belrose 1963), and by the small US satellites Injuns 3 and 5 (see, e.g., Gurnett and O'Brien 1964). A global map of lightning is derived from the detection of VLF sferics measured in 1972 by the British satellite Ariel 4 (Bullough et al. 1975).

Optical detections of lightning were made by photometers on the Orbiting Solar Observatory (OSO-B or OSO-2, Vorpahl et al. 1970) and then mapped in more detail by OSO-5 (Sparrow and Ney 1971). These photometers were saturated by moonlight (and sunlight) and therefore were restricted to observations during the new moon. The field of view of these instruments was of the order of a few square degrees (a few $\times 10^{4} \mathrm{~km}^{2}$ ), and in $\sim 200 \mathrm{~h}$ of observation spread over 15 months, about 7000 lightning strokes were detected in about 1000 storms, revealing 
Table 1 Timeline of lightning studies. Venus dates correspond to relevant publications, rather than data acquisition, generally only a year or so earlier

\begin{tabular}{|c|c|c|}
\hline & Venus & Earth \\
\hline 1959-1964 & $\begin{array}{l}\text { Mariner } 2 \text { encounter with } \\
\text { Venus; hot greenhouse } \\
\text { atmosphere identified }\end{array}$ & $\begin{array}{l}\text { Whistlers first observed by } \\
\text { satellites - Vanguard III, } \\
\text { Alouette, Injuns } 3 \text { and } 5\end{array}$ \\
\hline 1967 & $\begin{array}{l}\text { First in situ } \\
\text { measurements-Venera } 4\end{array}$ & \\
\hline 1970-1 & & $\begin{array}{l}\text { Optical flashes mapped by } \\
\text { OSO-2 and OSO- } 5 \text { satellites }\end{array}$ \\
\hline 1972 & Venera 8 reaches surface & \\
\hline 1975 & $\begin{array}{l}\text { Veneras } 9 \text { and } 10 \text { landers + } \\
\text { Orbiters. V-9 orbiter records } \\
\text { possible flashes }\end{array}$ & $\begin{array}{l}\text { RF lightning emissions } \\
\text { mapped by UK satellite Ariel } \\
4\end{array}$ \\
\hline 1979 & $\begin{array}{l}\text { VLF Discharges measured by } \\
\text { Venera } 11,12 \text { landers }\end{array}$ & \\
\hline 1979-80 & $\begin{array}{l}\text { Pioneer Venus Orbiter } \\
\text { detects electric ELF whistlers }\end{array}$ & \\
\hline 1983 & $\begin{array}{l}\text { Veneras } 13 \text { and } 14 \text { confirm } \\
\text { VLF discharges }\end{array}$ & \\
\hline 1986 & $\begin{array}{l}\text { VEGA balloons float in Venus } \\
\text { atmosphere }\end{array}$ & \\
\hline 1989 & & $\begin{array}{l}\text { NLDN provides continuous } \\
\text { US continental-scale } \\
\text { lightning mapping }\end{array}$ \\
\hline 1989 & $\begin{array}{l}\text { Magellan spacecraft } \\
\text { launched }\end{array}$ & Sprites first photographed \\
\hline 1994 & & $\begin{array}{l}\text { Terrestrial gamma-ray flashes } \\
\text { (TGFs) discovered }\end{array}$ \\
\hline 1997 & & $\begin{array}{l}\text { FORTE satellite: both optical } \\
\text { and RF detections TRMM } \\
\text { satellite studies storms and } \\
\text { lightning }\end{array}$ \\
\hline 2004 & & $\begin{array}{l}\text { DEMETER satellite. World- } \\
\text { Wide Lightning Network } \\
\text { (WWLN) established }\end{array}$ \\
\hline 2007 & $\begin{array}{l}\text { Venus Express detects } \\
\text { magnetic ELF Whistlers }\end{array}$ & \\
\hline 2008 & & C/NOFS satellite \\
\hline 2010 & Akatsuki launched & \\
\hline 2016 & & $\begin{array}{l}\text { GOES-16 with Geostationary } \\
\text { Lightning Mapper }\end{array}$ \\
\hline
\end{tabular}

graphically the enhancement of lightning activity over land relative to the oceans at the same latitude. Surveillance by flash meters on US VELA satellites (installed to detect the optical emission from nuclear detonations) revealed a small population of particularly intense lightning discharges (Turman 1977) and later dedicated lightning sensors on the Defense Meteorological Support Program (DMSP) satellites gave additional information on the optical power distribution of lightning flashes overall (Turman 1978; see also Christensen et al. 1979).

Modern satellite sensors dedicated to lightning mapping (e.g., the Lightning Imaging Sensor (LIS) on the
Tropical Rainfall Mapping Mission (TRMM), the Optical Transient Detector (OTD) (see, e.g., Finke 2009), and more recently, the global lightning imager on GOES-16 have yielded systematic observations of activity, enabling correlation with geographical or convective parameters. There have also been satellite missions dedicated to the study of lightning-related phenomena, notably the Fast On-orbit Rapid recording of Transient Events (FORTE) and Communications/Navigation Outage Forecasting System (C/NOFS), both of which carried optical flash detectors (photodiodes) as well as antennas to measure electromagnetic signatures. These observations (e.g., Fig. 5), and those from a related instrument (Global Lightning and Sprite Measurements on Japanese Experiment Modules JEM-GLIMS on the International Space Station, e.g., Sato et al. 2015), have given us simultaneous views of different phenomena associated with discharges, phenomena which have only been studied separately at Venus. There is also a powerful synergy between the ground-based networks and spacecraft sensors since they can perform intercalibrations to assess detection thresholds and efficiencies.

\section{Venus observation review}

In this section, we review pertinent details of the various Venus observations, arranged chronologically. The key parameters are summarized in Table 2.

\section{Veneras 11-14 lander electromagnetic observations}

Observations by the Veneras 11 and 12 probes, which descended to Venus' surface in December 1978, were the first strong report of lightning on Venus (Ksanfomality et al. 1979). Note that although the Venera 9 orbiter observations (see next section) were acquired earlier, their interpretation as lightning was not developed (Krasnopolsky 1979; submitted November 10, 1979) until after Ksanfomality's Venera 11/12 paper was published in the May/June 1979 issue of (originally submitted in February 1979).

The Veneras 11 and 12 probes carried an instrument suite called "Groza" (thunderstorm-a clear indication of the purpose of the system) which comprised a magnetic field antenna (a loop) to detect sferics and a microphone to detect thunder. Signals in two wavebands (at 10 and $36 \mathrm{kHz}$ ) were recorded. Veneras 13 and 14 carried an improved instrument (Groza-2) which also included a seismometer, Fig. 6.

The acoustic element of the instrument was not useful for detecting thunder during descent, in that, aeroacoustic noise of the air rushing past provided too strong a background for sensitive detection. On the surface, some lander-generated noise was identified, and the background signal level was in fact used to estimate the wind speed on Veneras 11 and 12, but no thunder was detected. 


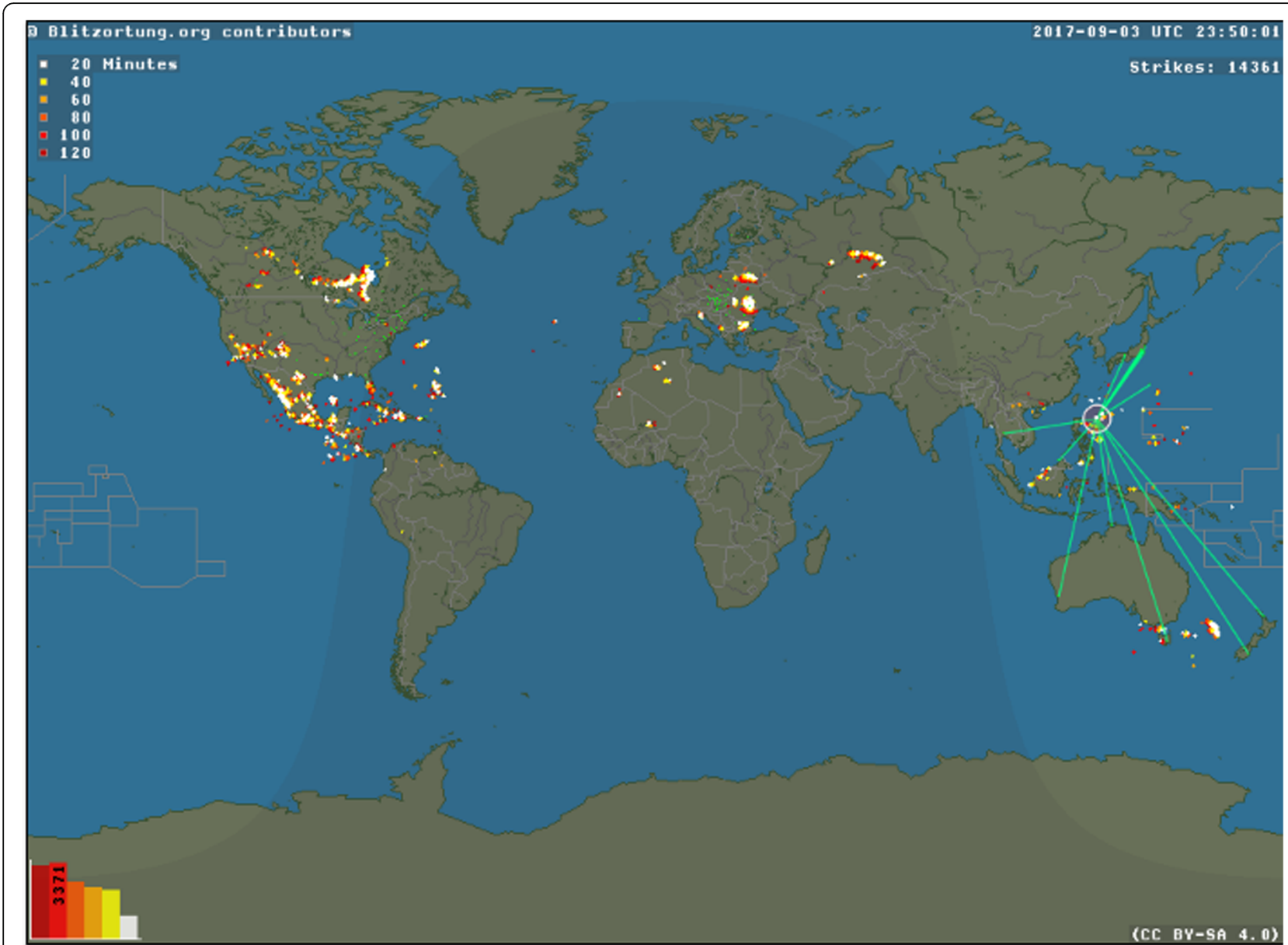

Fig. 4 Map of lightning activity in a $2 \mathrm{~h}$ period, detected more or less globally (coverage in South America and Africa by this amateur network is somewhat sparse of stations, which need only a small VLF receiver and an internet connection). A single recent strike is detected (lines) by stations from Japan to Australia and New Zealand, allowing its location in the Philippines-some $8000 \mathrm{~km}$ from New Zealand — to be reconstructed (circle) within a second or so. It is also apparent from this plot that there may often exist regions thousands of kilometers across where no lighting is present at a given time. Creative Commons license-by contributors to the Blitzortung network

The electromagnetic field sensor detected substantial activity, which showed a different vertical profile for each lander (suggesting that the signals were not artifacts). Usually, these have been displayed together with scales adjusted; it is instructive here to show them on a common scale Fig. 7.

Ksanfomality et al. (1979) and Ksanfomality (1980) claim that some of the detected bursts showed a periodicity commensurate with the slow rotation of the Venera 11 lander during the latter part of the descent, consistent with spin modulation due to the directionality of the antenna as it swept past a distant (i.e., of small extent in azimuth) source. However, this suggestion does not seem quite consistent with the measurements of the probe rotation from angular velocity sensors $\left(\sim 7^{\circ} / \mathrm{s}-\right.$ see Fig. 4 of Karyagin et al. 1980); the combination of this rate (50 s period) and the bi-lobed sensitivity pattern of the antenna should lead to a $25 \mathrm{~s}$ period modulation of a distant source, not the 40-80 s modulation observed. Furthermore, inspection of the radiation pattern of the antenna (Fig. 10 of Ksanfomality et al. 1983) suggests that the sensitivity varies with azimuth by a factor of 2-3, yet the observed change in signal amplitude appears rather larger. Thus, an alternative interpretation advanced in the present review is that in fact the pseudoperiodic variations are bursts of the original emission (implying only one to four sources were being observed, each generating one or a few bursts), rather than spin modulation of a single continuous source.

On Venera 12, one electromagnetic burst was recorded after landing. The burst (see Fig. 10 later in this article) lasted the entire observation window of $8 \mathrm{~s}$, these windows being repeated at $3-4 \mathrm{~min}$ intervals. This sparse sampling only constrains the burst to have a duration of between 8 and 360 s. No bursts were recorded on the surface by other landers (a total observation period of about $2 \mathrm{~h}$.) 


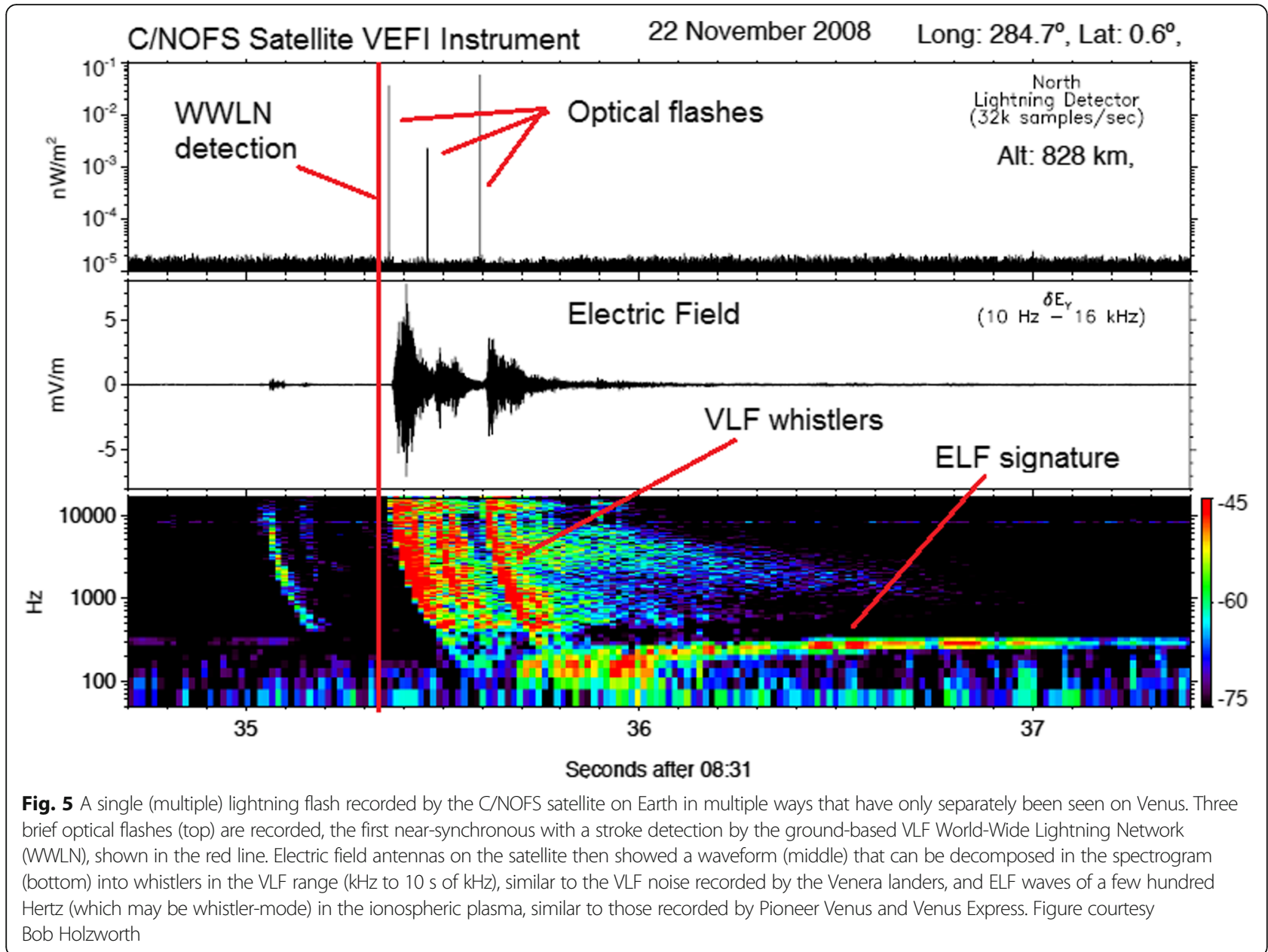

The near-continuous activity generally observed by the probes during most of the descent (the Venera 11 instance above notwithstanding) implies that if the activity is typically in 5-70 s bursts, the observation (instrument plus signal propagation characteristics) was sensitive enough to detect bursts from long enough distances that a sufficient number of sources was detectable at any moment to prevent gaps being observed between bursts. If we ignore for a moment that the probes were descending, we can consider each record as a time series. For Venera 11 (see, e.g., Fig. 2. of Ksanfomality et al. 1983), the activity was moderate $\left(\sim 20 \mathrm{uVm}^{-1} \mathrm{~Hz}^{-0.5}\right)$ between 0530 and $0545 \mathrm{~h}$ (60 to $30 \mathrm{~km})$ and strong $\left(\sim 100 \mathrm{uVm}^{-1} \mathrm{~Hz}^{-0.5}\right)$ from then until $0605(15 \mathrm{~km})$ then moderate to the surface. For Venera 12 (ibid, Fig. 3) some sporadic activity (with 1-2 min variations) was seen for the first 15 mins of descent, then essentially zero for the next $25 \mathrm{~min}$, then moderate activity for the last $20 \mathrm{~min}$ of descent.

Considering the first part of Venera 11, if a single source causes $\sim 5$ bursts of $\sim 30 \mathrm{~s}$ duration (as indicated in the high-resolution record 0606-0611 previously interpreted as spin modulation-Ksanfomality et al. 1983; Fig. 8), then the continuous record seen 0546-0552 (ibid, Fig. 5) implies two or more sources within range, such that the bursts overlap.

Note that in addition to the averaged field strength (recorded with a $0.25 \mathrm{~s}$ time constant, and in some cases in the papers cited above plotted after averaging over $20 \mathrm{~s}$ periods), the radio system was also equipped with a pulse counter. This indicated (Ksanfomality et al. 1979) pulse rates (threshold not specified) from 1or 2 per second to 10 or 20 for part of Venera 11's descent, and the text indicates even higher levels were seen. Pulse counter data is also presented in Ksanfomality et al. (1982) for Venera 14, with a threshold of some $200 \mu \mathrm{V} / \mathrm{m} / \mathrm{Hz}^{0.5}$-at this quite high threshold, the rates were 0 to 2 pulses per $10 \mathrm{~s}$ above about $25 \mathrm{~km}$, with some periods of $5-7$ pulses per $10 \mathrm{~s}$ below that level.

The possibility of some artifact (e.g., noise generated by aerodynamic flutter during descent) does not appear to have been discussed in detail in the literature. However, a slow systematic (smooth) altitude dependence would be expected, as the vehicles' terminal velocity slowed as they reached the denser lower atmosphere-such a dependence 


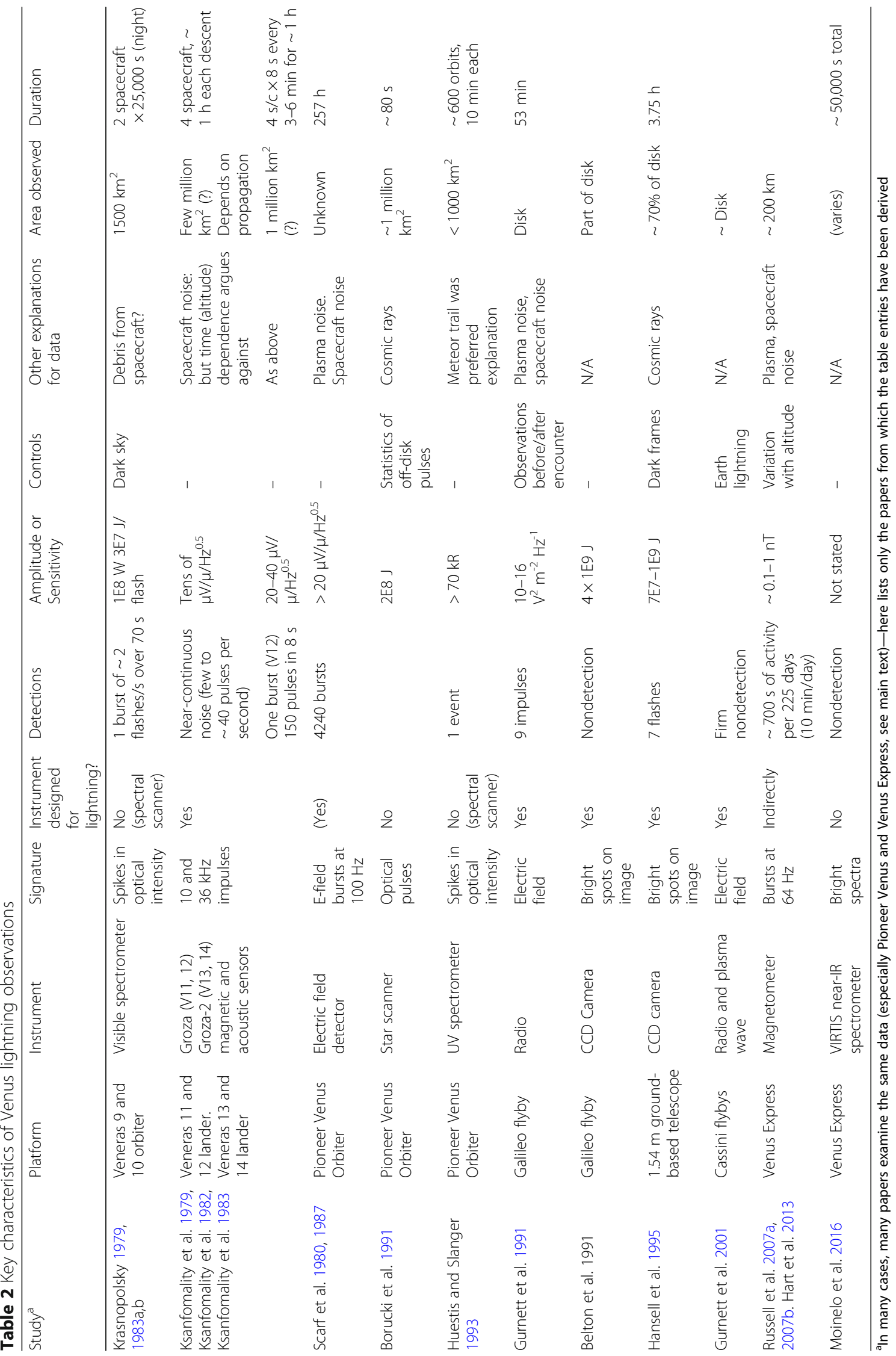




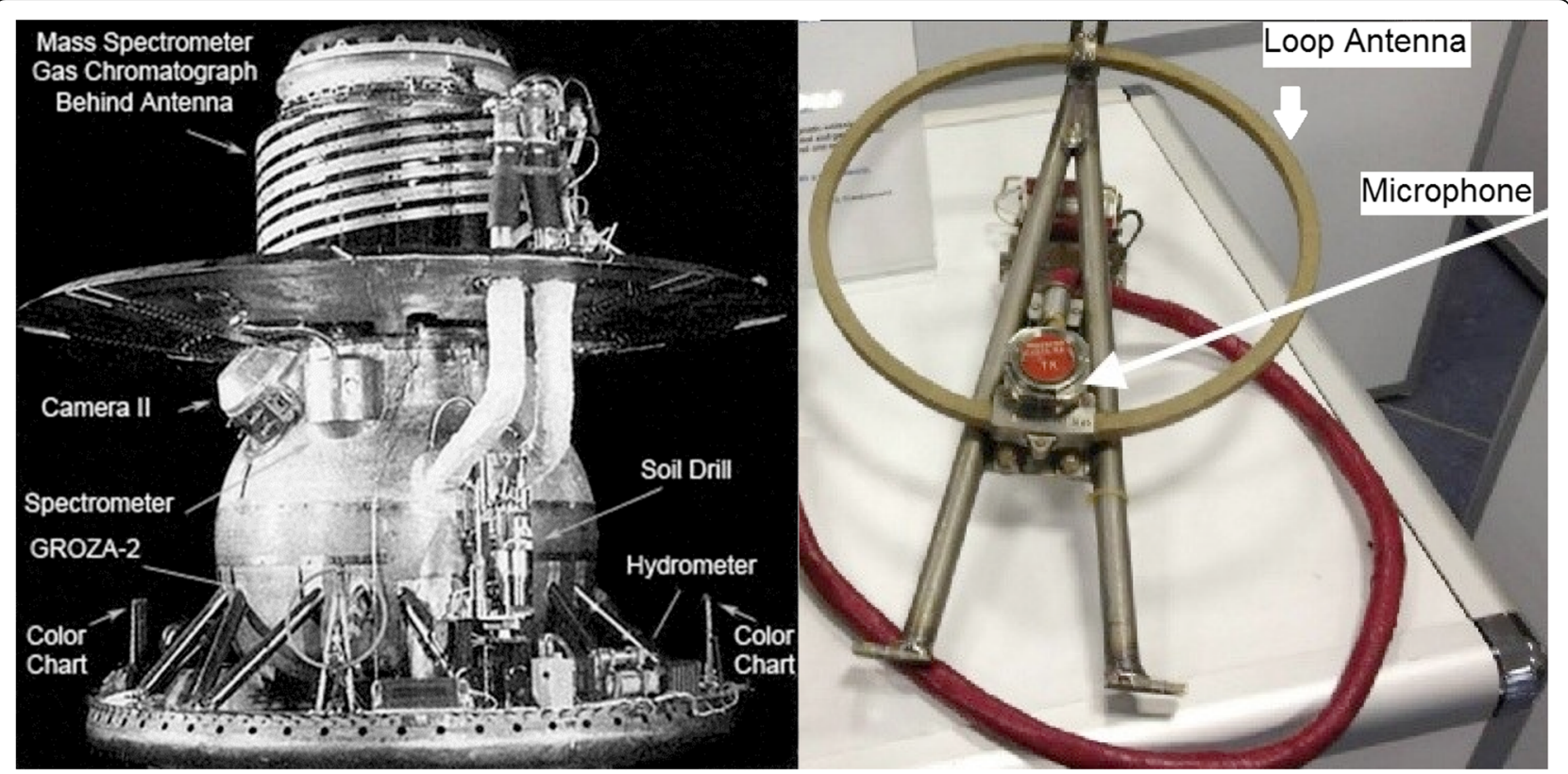

Fig. 6 The Venera 13 lander (left) with major systems noted (figure courtesy W. Huntress) - the GROZA-2 label points to the location of the loop antenna mounted externally just above the shock-absorbing landing ring. The disk structure near the top stabilized the probe during descent after the parachute was released. The GROZA-1 instrument is shown at the right (figure courtesy L. Ksanfomality) showing the loop antenna and mounting strut, together with a microphone for detecting thunder-note the heavy-duty insulation on the cable to protect it from the hot corrosive Venus atmosphere

was not observed. Further, it is seen (e.g., Ksanfomality et al. 1983, Fig. 10) that the signals do not cease abruptly at impact but rather fall off within the last few hundred meters of descent, more consistent perhaps with terrain obscuration of signal propagation. (The possibility of near-surface atmospheric composition changes causing radio absorption cannot be completely excluded, however). Finally, specifically to test whether charging of the vehicle itself could be responsible for the observed signals, a discharge current meter was installed on the Groza-2 experiments on Veneras 13 and 14 (see Ksanfomality et al. 1982) - those results do not appear to indicate any strong local contribution to the observed discharges but may be consistent with the presence of charged dust in the Venus lower atmosphere (Lorenz 2018).

It is useful to put the Groza experiments in context with a similar investigation, the Lightning and Radio Emission Detector (LRD) on the Galileo Probe (e.g., Lanzerotti et al. 1992; Rinnert et al. 1989, 1998). It was noted that the noise background of this instrument was found to be higher in flight (due to the operation of a nearby radiometer instrument with an electric motor) than in laboratory/field tests.

It may also be noted that the LRD instrument detected between 10 and several hundred RF pulses per second throughout the descent (over 150,000 pulses total), whereas no optical lightning detections were claimed (the few hundred counted optical pulses being attributed to spinmodulated sunlight early in descent, or to cosmic rays-see
Rinnert et al. 1998). This underscores the comparative long-range ability of electromagnetic vs optical sensing (and makes the optical nondetection of the VEGA balloon at Venus perhaps unsurprising). The LRD used a ferrite coil antenna (i.e., sensing the magnetic component of the signal, like the Groza instruments) and counted pulses in narrow bands at 3, 15, and $90 \mathrm{kHz}$, with the lowest frequencies seeing highest activity; sensed pulse amplitudes reached a few tens of nanotesla. The LRD detected appreciable azimuthal anisotropies (i.e., preferred source directions).

Terrestrial tests of the LRD showed that intensity fell off with increasing frequency approximately as $\mathrm{f}^{-2}$; such a strong fall-off was also seen at Jupiter (Rinnert et al. 1985). The Groza instrument at Venus found a spectral index varying between 0.5 and 2 , typically 1 . This fall-off seems consistent with an interpretation of the signals as due to electrical discharges. Note that the sometimes challenging units of electromagnetic observations have perhaps limited external scrutiny into these results-for example, even though a magnetic antenna was used, (Ksanfomality et al. 1979, Ksanfomality et al. 1983 hereafter referred to as K83) expresses the Groza signals as electric field intensity-e.g., the $10 \mathrm{kHz}$ signals on Venera 12 (K83 Fig. 3) reaching a value of $\sim 15 \mu \mathrm{V} / \mathrm{m} /$ $\mathrm{Hz}^{0.5}$ (recorded over a bandwidth of $1.6 \mathrm{kHz}$ ) or a peak field of $0.6 \mathrm{mV} / \mathrm{m}$. For classic electromagnetic propagation in free space, the electric field $E$ relates to the magnetic field $B$ as $E=c B$, with $c$ being the speed of light-note that this relation does not hold for the 


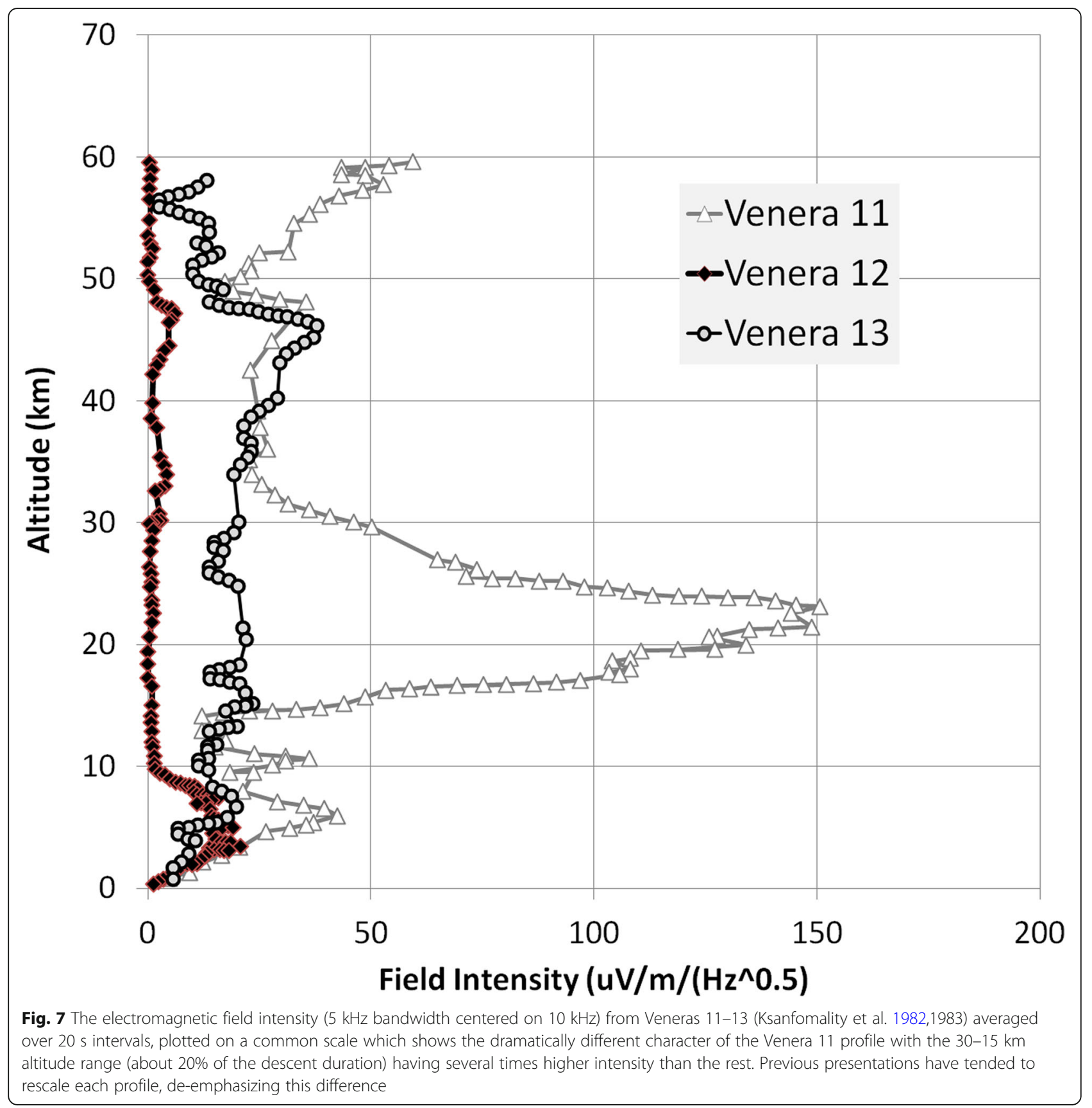

whistler-mode propagation in a plasma), and so, this corresponds to $0.002 \mathrm{nT}$, or $5 \times 10^{-5} \mathrm{nT} / \mathrm{Hz}^{0.5}$. The Galileo sensors at Jupiter, by contrast, recorded a power spectral density of up to $10^{-3} \mathrm{nT}^{2} / \mathrm{Hz}$ or $\sim 1 \times 10^{-6} \mathrm{nT} /$ $\mathrm{Hz}^{0.5}$ at a similar frequency $(15 \mathrm{kHz})$, a significantly lower level than Venus. On the other hand, a handful of waveforms were recorded by Galileo, the largest having a peak amplitude of a couple of tens of nanotesla (Lanzerotti et al. 1996; Rinnert et al. 1998).

In many respects, the Groza records are among the richest datasets pertaining to possible Venus lightning. Their presentation in various graphical forms in Ksanfomality et al. 1979 and 1983 is useful, but the examination with new statistical methods would benefit from access to original digital data, which is unfortunately not publicly accessible (sadly, also true of the Galileo LRD experiment).

Note that Ksanfomality's papers (1982, 1983) describe anomalies encountered by the Pioneer Venus probes as circumstantial support for electrical activity. While at the time, the possibility of some kind of discharge had been considered one possible explanation for these anomalies (the failure of external temperature sensors 


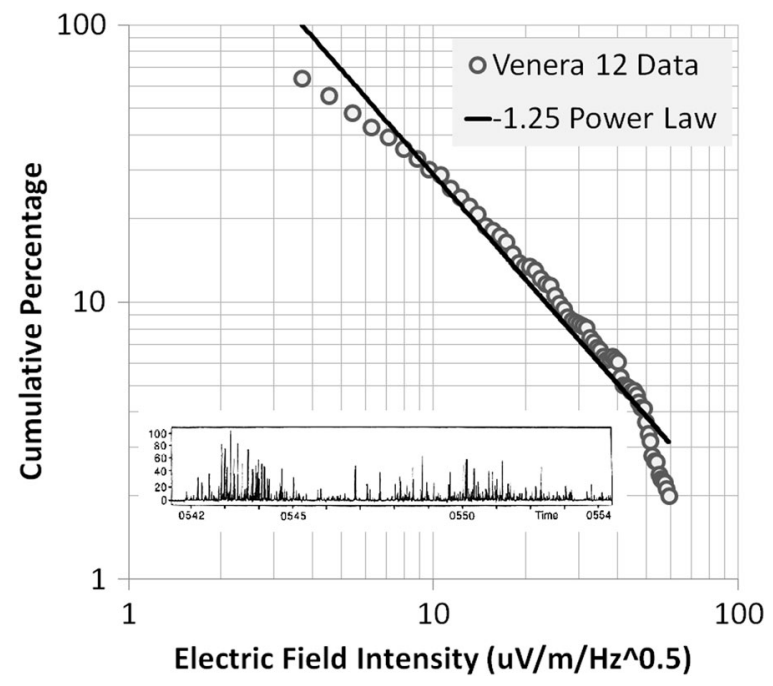

Fig. 8 Amplitude distribution of pulse heights (inset) recorded at a high data rate during part of the Venera 12 descent (see, e.g., Ksanfomality et al. 1983). About $30 \%$ of the time, the amplitude was at the noise level of $\sim 5 \mathrm{uV} / \mathrm{m} / \mathrm{Hz}^{0.5}$ — spikes of $\sim 100$ occur less than $1 \%$ of the time. The data (analyzed here by digitizing the plotted figure) do not permit robust discrimination of a power law from a broken power law or an exponential; the single power law with an exponent of -1.25 is shown as an example, although there is some hint of a steeper slope at the high end of the curve (right). The distribution arises either from an intrinsic amplitude distribution, or because discharges occur at a variety of ranges, or both. The distribution is also broadly consistent with the aggregate of results shown in Fig. 7

on all four probes, at the same altitude of $\sim 12 \mathrm{~km}$ ) these anomalies have since been attributed to a failure of electrical insulation in the Venus environment at this altitude (e.g., Seiff 1995; Harland and Lorenz 2006) and so should not be considered as indicating electrical activity (although they do not exclude it either).

\section{Venera 9 and 10 orbiter spectrometer}

These observations, initially reported in Krasnopolsky (1979), are discussed at rather more length in Krasnopolsky (1983a, 1983b, 2006). As this UV-visible-NearIR spectrometer scanned over $10 \mathrm{~s}$ from 300 to $800 \mathrm{~nm}$, observing a $160 \times 9 \mathrm{~km}$ patch of the Venus nightside, the recorded light level saw several irregular jumps-seven such scans had these jumps. Interpreting this as a time series rather than a spectrum, there was a $70 \mathrm{~s}$ series of flashes, about two per second, each lasting about $250 \mathrm{~ms}$, each of about $3 \times 10^{7} \mathrm{~J}$ of optical energy. Although claimed to be "similar to the duration of a flash on Earth," these durations (much longer than the instrument response time of $5 \mathrm{~ms}$ ) are puzzling. The observation was at $9^{\circ} \mathrm{S}$ around $7 \mathrm{pm}$ local solar time; the "thunderstorm region" is described as being of $50,000 \mathrm{~km}^{2}$ area, presumably derived by mapping the instrument footprint migration during the $70 \mathrm{~s}$.
One point to note is that in fact, this event was seen during the very first night observation of the instrument, perhaps when instrument anomalies would be more likely to occur. A further consideration is that while no localized Venus emission interpreted as lightning was recorded by the instrument on Venera 10, the light was unexpectedly measured off-disk and was interpreted as a dust trail from a comet Krasnopolsky and Krysko, 1979. The presence of a dust trail (something no mission to Venus before or since has indicated) cannot be ruled out entirely but is at least superficially improbable. Instead, it is possible that both this observation and/or the Venera 9 "lightning" burst may have been caused by light reflected from some material (e.g., thermal blanket) released from the spacecraft: a tumbling reflector could give quasiperiodic flashes with durations consistent with the $0.25 \mathrm{~s}$ durations observed. The star tracker on Magellan was spoofed by particles shed from its that spacecraft's thermal blankets when solar wind conditions led to surface charging (e.g., Harland and Lorenz 2005). It is also reported that the Venera 9 instrument temperatures increased from 20 to $60{ }^{\circ} \mathrm{C}$, during its 2-month mission, a factor which degraded the sensitivity of the spectrometer instrument (Krasnopolsky 1983a).

When considered qualitatively, "Venera 9 saw lightning, but some aspects of the observation are puzzling." A quantitative perspective, however, is much more illuminating. An important quantity recently explained (Krasnopolsky, personal communication, June 2017) to the author of the present paper is the duration of subsequent nightside observations (for Veneras 9 and 10 combined) where no lightning features were observed, $50,000 \mathrm{~s}$. Thus, one "burst" of $70 \mathrm{~s}$ of emission was seen in about $14 \mathrm{~h}$ of observation of an area $\sim 1500 \mathrm{~km}^{2}$, the activity being present $\sim 0.1 \%$ of the time.

Krasnopolsky claims that the spikes are enveloped somewhat by the optical sensitivity of the instrument (i.e., fewer/weaker flashes at the ends of the passband, whereas electrical noise or cosmic rays might be expected to be uniform with time/wavelength), supporting an external optical origin of the signal. However, this is also fully consistent with the sunlight reflections-from-debris hypothesis suggested above. If the signal was really due to lightning, it imposes an altitude constraint for the optical emission (as noted by Krasnopolsky 2006) in that the blue end of the spectrum at $20 \mathrm{~km}$ or below (i.e., volcanic lightning) would be attenuated severely by the atmosphere, and thus, whatever light was observed by Venera 9 had to come from above the deep atmosphere. However, since lightning emission has a highly nonuniform line emission spectrum (e.g., Borucki et al. 1985, 1996), the somewhat uniform peak amplitudes observed by Venera 9 seems perhaps more consistent with periodically reflected sunlight. 


\section{Pioneer Venus electric field detector}

The Pioneer Venus Orbiter was placed in December 1978 into an elliptical polar orbit around Venus with a $24 \mathrm{~h}$ period. It carried an electric field instrument which measured the power of electric field variations in four narrow wavebands. Taylor et al. (1979) and Scarf and Russell, 1983 reported that signals seen over nightside periapses, most prominently in the $100 \mathrm{~Hz}$ band, could be interpreted as whistler-mode emissions from lightning. These signals were "impulsive" in the sense of being short compared with the $0.5 \mathrm{~s}$ sampling interval and the $0.7 \mathrm{~s}$ decay time of the instrument. Because the spacecraft environment was noisy in sunlight, these signals could only be reliably detected at night, and they were detected only at low altitude (e.g., Scarf et al. 1980), which given the parameters of the orbit, meant low latitudes.

A variety of plasma phenomena can occur in space, and alternative explanations were offered for these signals and an extensive debate in the literature ensued. We do not recapitulate the blow-by-blow debate here but refer the reader to comprehensive reviews by Russell (1991) and Grebowsky et al. (1997) Fig. 9.

For the present discussion, we may note that while all observations (electromagnetic or optical) may suffer noise or artifacts, there are features of the signals that are claimed to be consistent with a lightning origin, notably their altitude dependence.

Scarf et al. (1987) reported identifying 4240 bursts in the first 2124 orbits, at altitudes between 150 and $2900 \mathrm{~km}$, indicated by them as a total observation period of $257 \mathrm{~h}$. Then, whatever phenomenon a "burst" actually corresponds to-perhaps passage over a thunderstorm-there were about 15 per hour. Note that the "new" burst definition used by Scarf et al. (1987), counting short events distinctly, corresponds to a rate five times higher than that used previously (assessing whether a signal existed in a $30 \mathrm{~s}$ window or not.) A more elaborate analysis was made by Ho et al. (1991) who attempted to deconvolve the response time of the instrument-in effect counting any $0.5 \mathrm{~s}$ window with measureable "extra" energy as an event-see Fig. 10. This yielded the rather high rate of $\sim 0.14$ events per second.

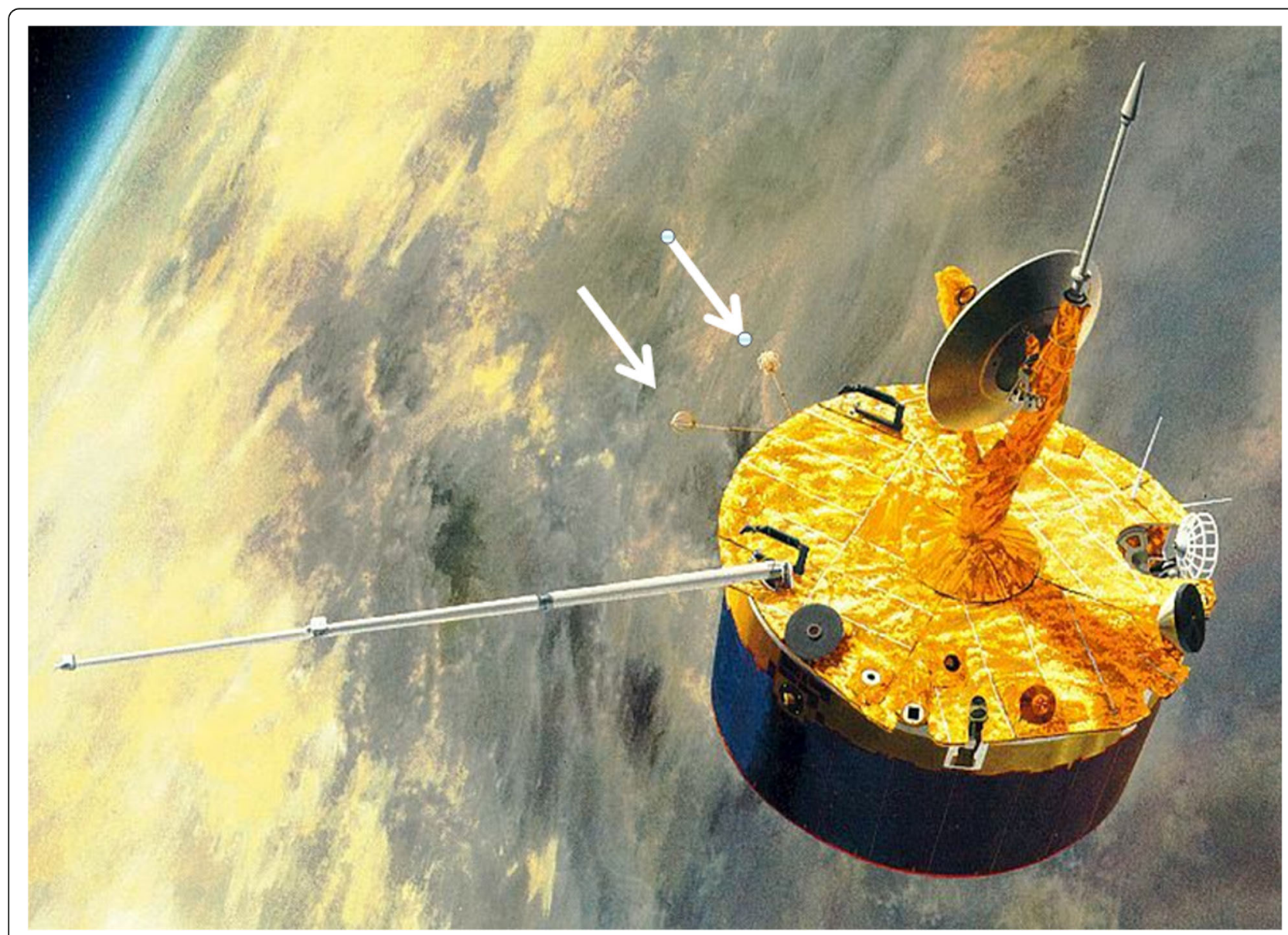

Fig. 9 NASA artists impression of the Pioneer Venus orbiter. The Orbiter Electric Field Detector (OEFD) measures the potential between two wire mesh sphere electrodes (arrowed) 


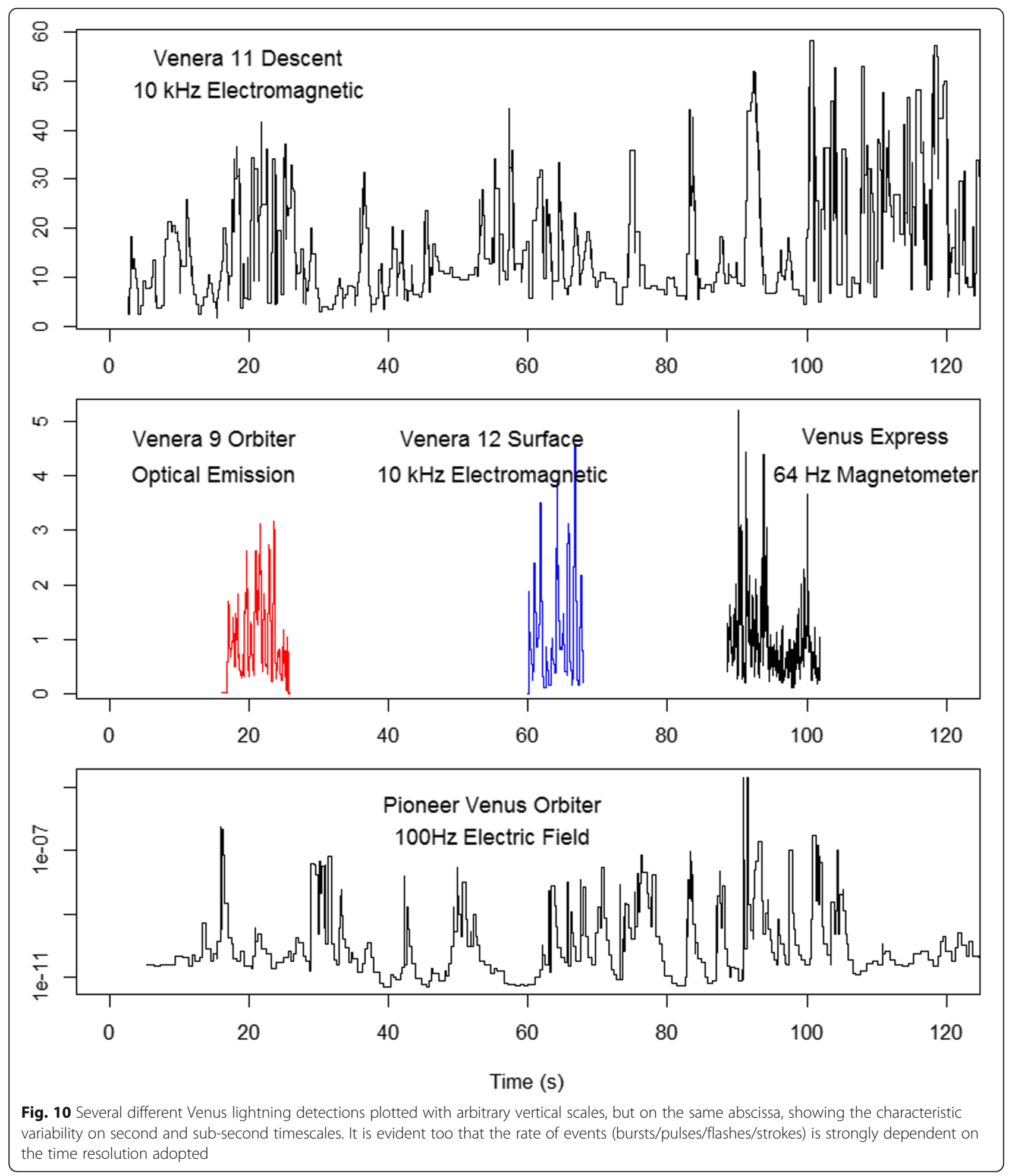

Although some claims of geographical association of whistler detections with elevated terrain (presumed to be volcanic) were made (e.g., Scarf et al. 1987), sampling biases may not have been fully taken into account, and this correlation is now considered weak at best-one refutation is by Taylor Jr and Cloutier (1986). ${ }^{1}$
Considerably more robust, however, is the finding that activity appeared to be concentrated in the duskmidnight sector, with much less in the midnight-dawn sector. Note that whereas on Earth, most convection occurs in the afternoon when solar heating is strong, on Venus convection may instead be driven by cloud-top 
cooling (e.g., Imamura et al. 2014) at night. This latter scenario would probably cause peak convective lightning activity in the dusk-midnight sector, as observed.

\section{Pioneer Venus optical}

Borucki et al. (1981, 1991) examined data from the star scanner on the Pioneer Venus Orbiter-an instrument and data-mining analysis much like that of Sparrow and Ney (1971) at Earth. Borucki et al.'s nondetection of events (or rather a detection rate that did not exceed the false alarm background due to energetic particles) in fact derived from only $450 \mathrm{~s}$ of effective search time (Borucki et al. 1981; another $88 \mathrm{~s}$, but covering a wider area, was added in further analysis, Borucki et al. 1991). The short observation period results from the fact that the observations relied on lightning emissions not being observed directly but rather scattered into the detector as stray light-even the "ashen light" from the Venus nightside saturated the detector when observed directly. Despite this short observing time, the area-time product of a few $\times 10^{7} \mathrm{~km}^{2} \mathrm{~s}$ was enough to derive a useful upper limit on the flash rate of $1-4 \times 10^{-7}$ flashes $/ \mathrm{km}^{2} / \mathrm{s}$.

\section{Pioneer Venus ultraviolet spectrometer}

An optical anomaly was noted (Huestis and Slanger 1993) in the analysis of data from the Pioneer Venus Orbiter ultraviolet spectrometer, whose primary purpose was to investigate the nightglow between 150 and $360 \mathrm{~nm}$ wavelength. In one observation (orbit 75), three successive scans were observed to have a strong emission (at wavelengths matching the $\mathrm{N}-\mathrm{O}$ band system). These short-wavelength scans had an interval of $24 \mathrm{~s}$, as the spacecraft spun with a $12 \mathrm{~s}$ period and short-wavelength (155-258 nm) and long-wavelength $(258-360 \mathrm{~nm})$ scans were interleaved. No anomalous brightness in the two intervening long-wavelength scans was observed. One could interpret this as a $72 \mathrm{~s}$ long event with only shortwave emission in narrow bands, or perhaps just coincidence that the 3-5 major flashes (discarding those with only one or two photons-see their Fig. 9) over a $72 \mathrm{~s}$ period just happened to occur during the shortwave scans. It should be noted that the "strong emission," corresponding to $70 \mathrm{kR}$ (kiloRayleighs-where one $R=10^{10}$ photons $/ \mathrm{m}^{2} / \mathrm{s}$ ), was indicated by only about 60 photons in each scan, compared with a typical 30 photons due to the airglow.

Huestis and Slanger (1993) offered a meteor trail (900 km long!) as a possible explanation, considering this more plausible than a lightning or auroral origin. Their interpretation seems improbable but cannot be excluded. The observation seems incompatible with a direct lightning origin (even though Borucki et al. (1996) conclude that discharges in the Venus atmosphere would produce some UV light, it would be scattered or absorbed before reaching an orbiting detector if launched from the clouds.) The possibility, however, of it being due to upper atmosphere luminosity from electrical discharge (i.e., sprites, elves, etc.-phenomena which only became well-known in the 1990s, after this observation and analysis were completed) might bear reexamination. Indeed, Pérez-Invernón et al. (2016) present models of posssible mesospheric optical signatures of lightning (i.e., transient luminous events (TLEs, such as sprites and elves) but curiously do not cite the Huestis and Slanger work. They note that in addition to the green and red oxygen lines, nitrogen emission would occur in the UV and near-IR. As an example, a lightning discharge with a total released energy of $2 \times 1010 \mathrm{~J}$ would launch $2 \times 10^{20}$ green photons and $3.7 \times 10^{19}$ photons $120-280 \mathrm{~nm}$, much of which would be in the PV UVS passband.

UV observations were made (lasting a few tens of minutes around periapsis) over the first 2 years; only this single anomaly was reported. Thus, this single "burst" of $\sim 72 \mathrm{~s}$ was the only one in $\sim 1$ million seconds of observation.

\section{Pioneer Venus gamma ray detector}

The Pioneer Venus Orbiter in fact carried an instrument whose purpose was not to study Venus at all; the Orbiter Gamma-Ray Burst Detector (OGBD) was flown to help measure astrophysical gamma-ray bursts, by using timeof-arrival differences between it and other spacecraft in the solar system to triangulate the source direction. This instrument operated for some 14 years until 1993 when Pioneer Venus' orbit decayed. It was only a year afterwards that terrestrial gamma-ray flashes (TGFs) associated with lightning on Earth were discovered Fishman et al. 1994.

Lorenz and Lawrence (2015) reviewed the OGBD dataset archived on the National Space Science Data Center (NSSDC) to assess whether there was evidence of an enhancement of gamma-ray flux near Venus, but unfortunately, those data were too coarsely binned in time to permit any conclusion. Should high-time-resolution records be discovered (in contrast to astrophysical bursts, TGFs are only milliseconds long), the question might bear reexamination. The authors also modeled the propagation of gamma rays through the Venus atmosphere, to assess the altitude above which gamma rays would need to be released to be usefully detectable. They found that gamma rays from sources at $65-75 \mathrm{~km}$ altitude (depending on energy) are attenuated by a factor of 100 . Radiation and particle transport studies were performed by Bagheri and Dwyer (2016), with similar results. Should gamma-ray instrumentation be flown 
on a future Venus orbiter (e.g., to measure sulphur in the clouds), a high-time-resolution capability would be desirable to detect possible lightning flashes.

\section{VEGA balloon}

The two VEGA balloons deposited into Venus' atmosphere in 1985 floated for $\sim 48 \mathrm{~h}$ at an altitude of 50$55 \mathrm{~km}$. Each gondola was equipped with a photodiode light gauge, including an electronic high-pass filter to detect flashes. No flash detections were reported: Sagdeev et al. (1986) notes that the intermediatebrightness flash counter on VEGA 2 did increment once, indicating a possible flash, but the measurement is suspicious because it was made near the terminator (where varying cloud-top altitudes could cause strong changes in ambient illumination) and that the lower-level threshold counter should also have incremented but did not. The VEGA data have recently been restored and made available for the NASA Planetary Data System (PDS) Lorenz et al. (2018); it may be noted that the VEGA-2 lander pressure-temperature profile therein is the only high-quality in situ atmospheric dataset that reaches all the way to the surface of Venus.

Although the observation period was relatively long, it may be noted that the observation was mostly in the midnight-dawn sector of the Venus day (on Earth, the period least likely to see lightning). Furthermore, the detection area would have been relatively small, only a few tens of kilometers across at most, i.e., area of $\sim 1000 \mathrm{~km}^{2}$. The platform is pseudoLagrangian, being advected with the air mass. Thus, if one adopts the proposition that some air masses have lightning and some do not (e.g., due to moisture content), then the range of locations sampled is very small (in contrast, e.g., to an orbiter survey of similar duration). Thus, the nondetection is a rather weak constraint on lightning on Venus.

\section{Galileo radio}

Gurnett et al. (1991) reported the detection of nine electric field impulses over a period of $53 \mathrm{~min}$ during the Galileo spacecraft's Venus flyby in 1991 at about 4-5 $\mathrm{R}_{\mathrm{V}}$ (Venus radii), i.e., a range of about $20,000 \mathrm{~km}$. Although at the time, they reported that "lightning is the most likely source," the lead on this investigation has informed us (Gurnett, personal communication, 23 May 2017) that he no longer believes lightning to be responsible, noting that impulsive signals could arise from (1) spacecraft electronics, (2) plasma waves, (3) dust impacts, (4) thermal stresses that cause discontinuous mechanical motions that are coupled to the antennas via microphonic effects, and (5) other unknown effects. Although control observations were carried out during two $1 \mathrm{~h}$ intervals (when no impulses were seen), these were well before the Venus flyby and well after the Venus flyby. Notably, the high-voltage component of a plasma instrument (PLS) was active during the close approach period but was off during the control intervals. Thus, it is possible that the operation of the PLS high voltage unit close to Venus was responsible for the signals interpreted at the time as lightning. It may also be noted that if the impulses really were due to lightning, the observed rate is much lower than would be observed for terrestrial lightning at a comparable radial distance.

\section{Galileo optical}

Belton et al. (1991) examined nightside images of Venus acquired by the Galileo spacecraft during its flyby en route to Jupiter. Ten images were devoted to this lightning search; however, since exposure times were less than a second, the nondetection is not a strong constraint.

\section{Mt. Bigelow ground-based optical}

Hansell et al. (1995) installed the CCD detector at the $153 \mathrm{~cm}$ telescope located on Mt. Bigelow, Arizona (more popularly known locally as the "61-inch."), and searched for light flashes on the nightside of Venus. Their study carefully employed coronagraphic optics, using two masks designed in accordance with the specific geometry for each individual night of viewing. An occulting mask was used in the imaging plane, and a Lyot mask was used to block diffracted light by the edges and support structure of the secondary mirror. The CCD detector was operated at 18.8 frames/s for $\sim 30$ pixel images of Venus. The observations were made at mainly $777.4 \mathrm{~nm}$ (i.e., in the near-infrared-an atomic oxygen line expected from laboratory simulations of lightning discharge in a carbon dioxide atmosphere by Borucki et al. 1996); a few observations were made at $656.3 \mathrm{~nm}$ as a control. For eight nights in 1993, the total viewing time was $3 \mathrm{~h}$ at $777.4 \mathrm{~nm}$ and $45 \mathrm{~min}$ at $656.3 \mathrm{~nm}$. The dusk side of Venus was facing Earth. Seven events met the stringent criteria (including the requirement that an event must be seen on more than one pixel) that the experimenters used for isolating lightning flashes, as shown in Fig. 1. Six events were detected in the $777.4 \mathrm{~nm}$ line. The seventh occurred while observations were being made at $656.3 \mathrm{~nm}$. The $777.4 \mathrm{~nm}$ flashes occur at a rate of $2.7 \times 10^{-12}$ flashes $/ \mathrm{km}^{2} / \mathrm{s}$ and imply Venus lightning flashes with optical energies from $7 \times 10^{7}$ to $2 \times 10^{9} \mathrm{~J}$.

Although the statistics are rather poor, Hansell et al. (1995) did note that three of the flashes occurred within 10 min of each other, while some nights had no flashes at all, suggesting a possibly clustered behavior. However, the locations of flashes were distant from each other, suggesting this may have been a sporadic coincidence. The detection of a flash at $656.3 \mathrm{~nm}$ (the hydrogen-alpha line, not initially expected to yield lightning detections) was interpreted as being due to 
light from a carbon emission line at $658 \mathrm{~nm}$ identified in laboratory experiments simulating lightning discharge in various planetary atmospheres (Borucki et al. 1985; Borucki et al. 1996).

A remark on the flash duration is in order. Krasnopolsky's (1979) detections-see earlier-were about $250 \mathrm{~ms}$ long, not typical of terrestrial flashes (as had been claimed). The Hansell et al. (1995) data analysis procedure entailed subtracting a running average image (of the two frames before and the two frames after) from each image. Thus, if a flash were of $250 \mathrm{~ms}$ duration, it would have spanned all five frames, and the bias (average) image would contain just as much energy as the frame under study. In other words, the analysis procedure excluded long pulses of light. Note also that the analysis procedure excluded single-pixel events. The only events recorded, then, had an apparent span of many hundreds of kilometers, although the sources may have been rather smaller but blurred by the Earth's atmosphere (observations of Venus are necessarily made with Venus low in the sky and thus at large air masses, susceptible to seeing conditions). Note that some other phenomena do have durations of $250 \mathrm{~ms}$ (e.g., blue jets), and meteor fireballs or trails can have durations of the order of a second or longer (e.g., McAuliffe and Christou 2006).

Note that Hansell and colleagues repeated the experiment the following year (Hansell, personal communication, 2010), although since this was a null result and the concluding part of work for a thesis (Hansell, University of Arizona, 1996), no journal publication was made. This experiment used a dichroic splitter so that both the $778 \mathrm{~nm}$ and hydrogen-alpha line would be observed simultaneously. The same processing applied to the earlier imaging campaign failed to yield any detections at either wavelength, although it should be noted that the new observation was made on the sunrise side of Venus' dark disk (i.e., local solar times between about midnight and 6 a.m., where the electromagnetic results from Pioneer Venus seem to show a pronounced decrease in activity.)

\section{Cassini radio}

The Cassini flybys (Gurnett et al. 2001) provided a much better search for lightning at Venus than was available from the Galileo flyby. The reasons are as follows. First, the flyby altitudes for Cassini, 284 and $598 \mathrm{~km}$, were much closer than for Galileo, which would make the lightning signals stronger by a factor of 1600 to 10,000 in power. Second, because Cassini had longer antennas, its sensitivity was better than for Galileo, by at least a factor of 10 . Third, the integration time constant of the Cassini receiver $(1 \mathrm{~ms}$ for some of the observations) is much better suited to detect the very short impulses from lightning than the Galileo receiver, which had an integration time constant of about $100 \mathrm{~ms}$.
Furthermore, the ability of the Cassini instrument to detect lightning was explicitly demonstrated during the CassiniEarth flyby in August 1999, during which over 1000 impulses consistent with lightning were detected at radial distances inside $14 R_{E}$. That no impulses significantly above the receiver noise level were detected during either of the Cassini-Venus flybys (total observing time of several hours while viewing essentially the entire planet) allows us to make the very strong statement that "lightning similar to terrestrial lightning did not exist at Venus during the two Cassini flybys." Crudely, one might interpret the null result as indicating a flash rate lower than about one-thousandth of Earth's. Of course, this does not rule out the possibility that episodes of terrestrial-like lightning could occur at Venus during other times, such as occurs for the very episodic lightning at Saturn (intense lightning activity was observed in association with a large storm on that planet, around the equinox season in 2009, but relatively little activity has been detected by the 2004-2017 Cassini mission either optically or by radio before or since this one stormsee, e.g., Fischer et al. 2011).

\section{Venus Express magnetometer}

The most persuasive recent evidence for lightning are the transient AC magnetic field pulses observed by Venus Express (Russell et al. 2008a). Like other electromagnetic evidence, these suffer from the ambiguity of having alternative explanations (spacecraft artifacts, plasma noise, etc.), but the recurrent nature of the signals (having been observed hundreds of times) and the fact that their polarization and detection appear consistent with whistler-mode ELF emissions lend some support to the claim that they have a lightning-like origin.

Specifically, they have been observed close to the periapsis of Venus Express ( $250 \mathrm{~km}$ altitude; due to Venus Express's orbit, this happens nearly over the north pole), when magnetic field lines are inclined in such a way as to link the spacecraft with Venus' atmosphere. The signals are detected at $64 \mathrm{~Hz}$ (the sample rate of the magnetometer is limited to $128 \mathrm{~Hz}$ ) and have a typical amplitude of $0.1 \mathrm{nT}$, sometimes reaching $1.5 \mathrm{nT}$ (Daniels et al. 2012).

Hart et al. (2013) describe the bursts as lasting between $6 \mathrm{~s}$ and up to a minute. Note, however, that the spacecraft is moving at almost $10 \mathrm{~km} / \mathrm{s}$, so in $1 \mathrm{~min}$, the vehicle traverses about $600 \mathrm{~km}$. If the range sensed by the whistler-mode observation is only a couple of hundred kilometers, then it may be that the upper bound on burst duration is truncated not by the intrinsic duration of bursts of activity but by the duration of the visibility window of a given source.

Hart et al. (2013) report that bursts occupied about $1 \%$ of the time the spacecraft spent at about $250 \mathrm{~km}$ altitude, the occurrence falling off to higher altitudes $(\sim 0.3 \%$ at $390 \mathrm{~km})$, but also towards lower altitudes. 
Russell et al. (2008b) note that in the first Venus year of operation, there were 12,223 s of useful data, during which 61 bursts were detected, i.e., one per 200 s. They assumed that the magnetic field permitted detection only $25 \%$ of the time. They also make the reasonable (but unsupported) assumption that the detection samples a region $200 \mathrm{~km}$ in radius (roughly the spacecraft altitude above the ionosphere) or $0.027 \%$ of the surface and extrapolate to a rate of $18 / \mathrm{s}$ globally.

Some care is needed in that different definitions of the event or "burst" have been used. Daniels et al. (2012) show magnetometer waveforms and hodograms and describe the "components" as lasting around $100 \mathrm{~ms}$ (since the data are generated from heavily bandpass-filtered signals between 42 and $60 \mathrm{~Hz}, 100 \mathrm{~ms}$ corresponds to only a few "wiggles" of the signal) whereas Russell et al. (2007a) describe them as $0.2-0.5 \mathrm{~s}$. They show the peak rate of bursts defined that way as $\sim 0.0045$ per second at 200-225 km altitude, whereas the "reduced" burst rate, defined as the number of $5 \mathrm{~s}$ intervals containing such a signal as 0.0014 per second-thus on average, when a $5 \mathrm{~s}$ burst occurs, it contains $\sim 3$ smaller pulses.

These rates, based on several years of operation, are a disconcerting order of magnitude less than the initial report of Russell et al. (2007a). That study used 37 orbits (days) of data selected when the background noise due to the spacecraft reaction wheels was particularly low, such that bursts with a peak-to-peak amplitude of $0.2 \mathrm{nT}$ can be picked out. Reader attention is needed to note that the Daniels et al. (2011) counts of $0.2 \mathrm{nT}$ are for $0.2 \mathrm{nT}$ half amplitude-i.e., events double in amplitude compared with Russell et al. (2007a). Lightning events, like many other phenomena in nature, have highly skewed populations, and any attempt to compare counts without taking the detection threshold into account is hopeless (see, e.g., Lorenz 2009 for a similar problem with dust devils). Daniels et al. (2011) break their counts up into several amplitude bins $\longrightarrow 0.4 \mathrm{nT}$ events make up only $10 \%$ of the total of $>0.2 \mathrm{nT}$ events, so one might similarly extrapolate that $>0.1 \mathrm{nT}$ events are ten times more abundant, consistent with the Russell et al. (2007a) numbers. Russell et al. (2011) describe bursts as about $4 \mathrm{~s}$ long and having a rate of $0.05 / \mathrm{s}$ at peak. Thus, even considering observations from a single instrument, the event rate may vary by a factor of $\sim 40(0.0014$ to $0.05 / \mathrm{s})$ depending on the threshold and time window considered! The same caution applies to optical detections-see Fig. 11 and associated discussion later.

\section{Venus Express near-infrared}

Moinelo et al. (2016) examined nighttime data from the visible (280-1100 $\mathrm{nm}$ ) channel of the VIRTIS imaging spectrometer on Venus Express. Their search resulted in thousands of transient signal detections, but these could all be explained by cosmic rays impinging on the detector, and analysis showed that the events were randomly distributed along the spectral dimension, rather than being associated with some expected line emission from Venus' atmosphere. The total observing time was $\sim 50,000 \mathrm{~s}$ (Moinelo, personal communication, 2017).

\section{Ground-based optical (II)}

García Munõz et al. (2011) utilized narrowband fast imaging of the Venus disk from an array of ground-based telescopes. The search targeted the oxygen emission line at $777 \mathrm{~nm}$ which should be a prominent line in lightning (as on Earth-most terrestrial spaceborne sensors use a filter to isolate this wavelength to improve the signal to noise). Two sites (Calar Alto and Observatorio del Teide) and three instruments (AstraLux, FastCam, and Wide FastCam) were used for observations during November 2010 to January 2011. The analysis of the night-side imaging of Venus showed no signal of optical emissions. It is likely that many other optical surveys with negative results also exist since nondetections tend not to be reported (e.g., an anonymous reviewer of this paper suggested that the late D. Sentman at University of Alaska made such observations but no formal publication resulted).

\section{Implications and discussion \\ Synthesis of observations}

In Tables 3 and 4, we review the evidence outlined in the previous section. While indeed the reports are not mutually consistent with a simple picture of Earth-like lightning, some conclusions can be drawn, most notably that some sort of atmospheric electricity effect is present but that it yields neither optical flashes nor VLF radio emissions observable from space in anything like the frequency that occurs for Earth.

In principle, it might be possible to aggregate the observational constraints and apply them to models of lightning distribution (spatial, temporal, and amplitude) to test various hypotheses. For example, if lightning is exclusively due to volcanoes, sources will be geographically fixed and will have no local time dependence (although various observation efficiencies, e.g., the ionosphere, may have such dependence). However, the data at hand do not seem adequate to justify such an exercise-the Venera lander datasets are too brief, the Pioneer Venus results already dismissed as equivocal, while the Venus Express magnetometer results are confined to near the north pole and are likely conditioned more by propagation conditions than by local time or geographic effects on their sources.

Observations similar to those of Hansell et al. (1995) would be useful to repeat, even with telescopes of 


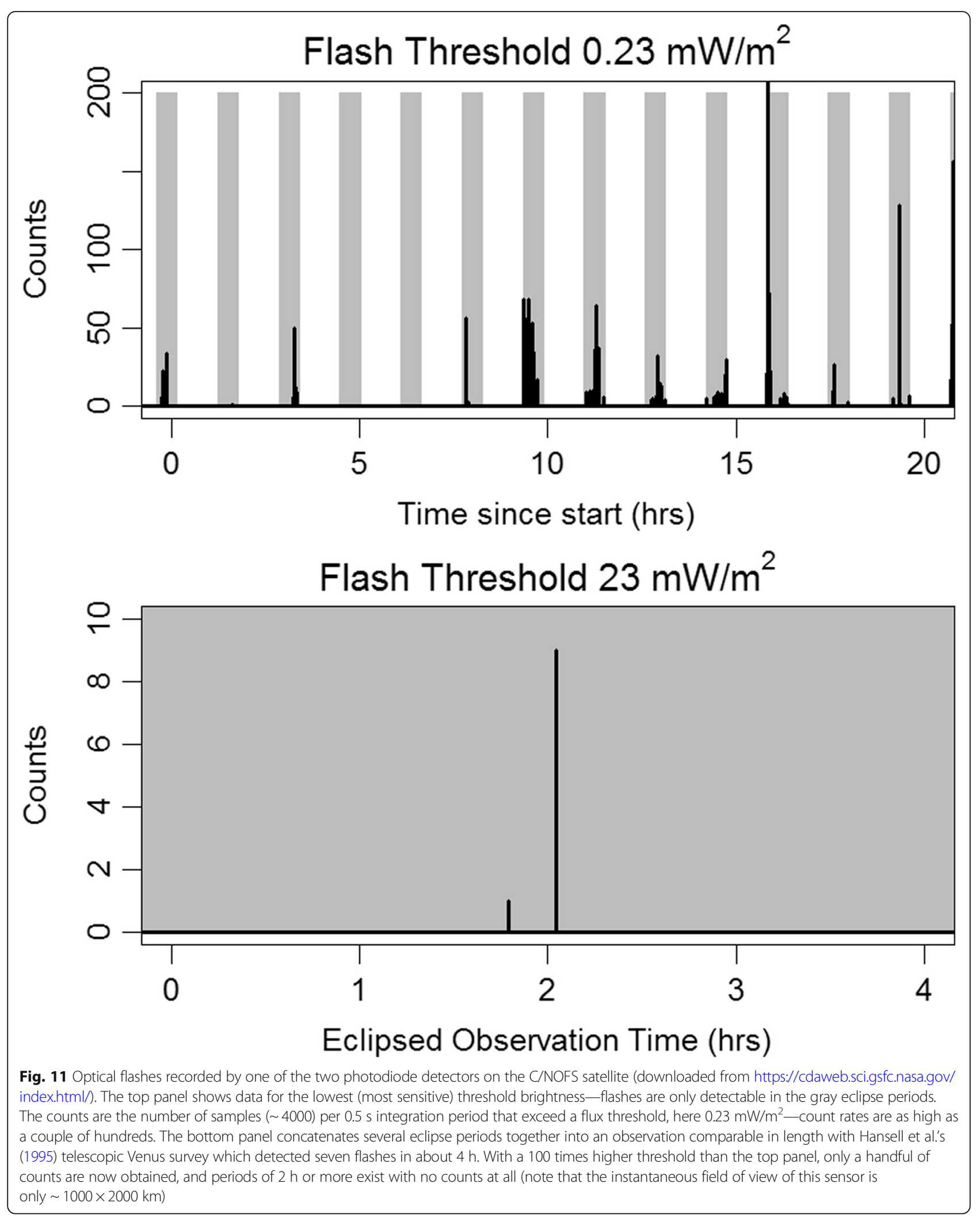


Table 3 Summary of characteristics of Venus electrical activity

\begin{tabular}{|c|c|c|c|}
\hline Property & $\begin{array}{l}\text { Estimate and } \\
\text { confidence }\end{array}$ & Support & Comment \\
\hline Rate of bursts & $\begin{array}{l}15 / \mathrm{h} \\
\sim 1 / \mathrm{min} \\
\sim 18 / \mathrm{h}\end{array}$ & $\begin{array}{l}\text { PV E-field bursts [30 s] (Scarf et al. 1987) } \\
\text { Venera } 11 \text { bursts } 13-17 \mathrm{~km} \\
\text { Venus Express bursts (see text) }\end{array}$ & \\
\hline Rate of pulses (during burst) & $\begin{array}{l}\sim 0.14 / \mathrm{s} \\
\sim 0.1-0.7 / \mathrm{s} \\
2-20 / \mathrm{s}\end{array}$ & $\begin{array}{l}\text { PV E-field pulses (Ho et al. 1990) } \\
\text { Venera } 14 \text { descent pulses (> } 200 \mu \mathrm{V} / \mathrm{m} / \mathrm{Hz}^{0.5} \text { ) } \\
\text { Venera } 11 \text { descent pulses (unknown threshold) }\end{array}$ & \\
\hline Duration of burst events & $\begin{array}{l}\text { Well-determined: } \\
\text { 5-100 s }\end{array}$ & $\begin{array}{l}\text { - Venera } 12 \text { surface burst }>8 \mathrm{~s} \text {, less than } \\
3-6 \text { min } \\
\text { - VEx magnetometer bursts } 6 \mathrm{~s} \text { to }>60 \mathrm{~s} \\
\text { - Venera } 9 \text { burst } 70 \mathrm{~s} \\
\text { - PV E-field bursts }\end{array}$ & $\begin{array}{l}\text { Overlaps between bursts on Veneras 11-14 } \\
\text { descent do not constrain burst duration }\end{array}$ \\
\hline Flash duration & Unclear & $\begin{array}{l}\text { - Venera } 9 \text { claims } \sim 250 \mathrm{~ms} \text { (long for terrestrial } \\
\text { lightning) but instrument response? } \\
\text { - Hansell ground-based detections }<100 \mathrm{~ms} \\
\text { (but 5-frame running mean bias subtraction } \\
\text { reduces sensitivities to flashes }>50 \mathrm{~ms} \text {, and } \\
\text { discards transients }>250 \mathrm{~ms} \text { altogether) } \\
\text { - Veneras } 11-14 \text { pulses } 10-60 / \mathrm{s} \text {, means up } \\
\text { to } \sim 8-50 \mathrm{~ms} \text { long }\end{array}$ & $\begin{array}{l}\text { Venus Express, Pioneer Venus ELF signatures } \\
\text { longer than "flash" due to propagation } \\
\text { delay, so no constraint (see Fig. } 5 \text { bottom } \\
\text { panel) }\end{array}$ \\
\hline Geographic distribution & Global? & $\begin{array}{l}\text { - PV OEFD detections mostly mid-latitude } \\
\text { (claimed association with highlands specifically } \\
\text { was not substantiated by data, but not } \\
\text { excluded either } \\
\text { - VEx MAG detections only made near north } \\
\text { pole (low altitude required for observation) } \\
\text { - Venera lander detections made at low } \\
\text { latitude, but long detection range gives } \\
\text { little localization }\end{array}$ & \\
\hline Source region size & $\begin{array}{l}<\text { few hundred } \\
\text { kilometers }\end{array}$ & $\begin{array}{l}\text { - Spin modulation of Venera } 11 \text { source } \\
\text { - PV, VEx cover } \sim 600 \mathrm{~km} \text { in } 60 \mathrm{~s} \\
\text { • Hansell flashes cover } 3-15 \text { pixels } \\
\text { ( } 2.2 \text { arcsec pixels each } \sim 600 \mathrm{~km} \text { across) }\end{array}$ & \\
\hline Local time distribution & $\begin{array}{l}\text { Strongest observed in } \\
\text { evening ( } 18-24 \text { h). But } \\
\text { few dayside } \\
\text { observations }\end{array}$ & $\begin{array}{l}\text { - Strongly indicated by distribution of PV } \\
\text { OEFD and VEx MAG bursts } \\
\text { - Statistics of optical detections too poor } \\
\text { to provide useful constraints }\end{array}$ & $\begin{array}{l}\text { Evening cooling of cloud-tops drives } \\
\text { convection? }\end{array}$ \\
\hline
\end{tabular}

Table 4 Summary of hypotheses regarding Venus lightning

\begin{tabular}{|c|c|c|c|}
\hline Scenario & Support & Comment/challenge & Conclusion \\
\hline $\begin{array}{l}\text { There is no electrical activity on } \\
\text { Venus }\end{array}$ & $\begin{array}{l}\text { - Sensitive Cassini search } \\
\text { yielded null result } \\
\text { - Various optical searches } \\
\text { have yielded null } \\
\text { results } \\
\text { - A priori theoretical } \\
\text { difficulty of charge } \\
\text { separation }\end{array}$ & $\begin{array}{l}\text { - Requires alternative mechanisms (e.g., local plasma noise) for all } \\
\text { orbital electromagnetic evidence (Pioneer OEFD, VEx } \\
\text { magnetometer) } \\
\text { - Also requires alternative mechanism for atmosphere/surface } \\
\text { electromagnetic evidence (Veneras 11-14) } \\
\text { - Implies Venera } 9 \text { optical detection spurious (not improbable per } \\
\text { the present paper) } \\
\text { - Implies ground-based optical detection spurious }\end{array}$ & Unlikely \\
\hline $\begin{array}{l}\text { Sporadic electrical discharges occur } \\
\text { with characteristics different from } \\
\text { Earth }\end{array}$ & $\begin{array}{l}\text { - Consistent with } \\
\text { electromagnetic } \\
\text { signatures } \\
\text { - Occasional optical } \\
\text { detections }\end{array}$ & $\begin{array}{l}\text { - If optical signals are present at all, perhaps they are transient } \\
\text { luminous events (TLE's, i.e., sprites or similar) } \\
\text { - Cassini radio nondetection was "unlucky"—ionospheric } \\
\text { conditions? }\end{array}$ & Not excluded \\
\hline Frequent lightning similar to Earth & $\begin{array}{l}\text { - Venera } 9 \text { original } \\
\text { interpretation }\end{array}$ & $\begin{array}{l}\text { - Sensitive Cassini search yielded null result, but detected ample } \\
\text { activity at Earth with similar observation } \\
\text { - Orbital electromagnetic signatures imply lower rates } \\
\text { - Various optical searches have yielded null results or low flash rates } \\
\text { - A priori theoretical difficulty of charge separation }\end{array}$ & Unlikely \\
\hline
\end{tabular}


somewhat smaller aperture (which are quite abundant). Modern digital video cameras allow high frame rates suitable for detecting transients, and the computer storage and processing hardware and software-demanding in the mid-1990s for this application-are easy to acquire. Notably, software to detect bright transients in planetary video sequences has been developed and made publicly available (e.g., http://pvol2.ehu.eus/psws/jovian_impacts/) and has been successful in detecting impact flashes on Jupiter and the moon (e.g., Hueso et al. 2013).

\section{Chemical evidence for lightning}

On Earth, lightning was the principal mechanism of nitrogen fixation prior to the evolution of nitrogen-fixing bacteria and the Haber process. It has been long noted (e.g., Krasnopolsky 1983; Bar-Nun 1980) that the abundance of $\mathrm{NO}$ or other nitrogen-bearing species could be profoundly influenced by lightning, and the observed abundance has been taken as at least circumstantial evidence for lightning. Krasnopolsky (2006) suggested an abundance of $5.5 \pm 1.5 \mathrm{ppb}$ below $60 \mathrm{~km}$ by ground-based telescopic observations and argued that this was consistent with a global flash rate is $\sim 90$ flashes/s for a flash energy $\sim 10^{9} \mathrm{~J}$ (of course, the chemistry only constrains the product of flash rate and energy-larger but rarer flashes would yield the same production.). The production of NO by shock chemistry associated with meteors has not been evaluated but could conceivably reduce the apparent need for lightning to yield the observed NO abundance.

\section{Lightning and volcanos}

In many respects, the study of present-day volcanism on Venus has parallels with the study of lightning. While the past modification of the Venus surface by volcanism is indisputable, the detection of the present-day activity is not. Such detection would of course be a scientifically appealing discovery, and a number of claims have been made. However, the indirect evidence (of changes in the sulphur dioxide abundance in the atmosphere) has alternative explanations. The claimed direct evidence of microwave (Bondarenko et al. 2010) and near-infrared (e.g., Shalygin et al. 2012) emission is subject in both cases to high false-positive susceptibility due to the background subtraction or modeling required to isolate a volcanic signature, and the claims are not widely considered adequate evidence to assert discovery.

In fact, the investigations of lightning on Venus and of present-day volcanism have not only scientific and sociological similarities but also intersections. It is often pointed out that lightning discharges occur in the ash plumes of volcanos on Earth, and in fact, the lightning networks such as WWLN are now used to remotely monitor volcanic activity, as in the case of the 2015 eruption of the Chilean volcano Calbuco (Van Eaton et al. 2016).
Some geographical associations of electric field signatures in Pioneer Venus data with regions on Venus were taken as circumstantial support of a volcanic lightning interpretation. However, the logic was in fact somewhat circular, and the associations were not statistically robust (e.g., Taylor Jr and Cloutier (1986). That said, such an association is not excluded either (e.g., Russell 1991).

Observations on future missions able to locate the sources of electrical discharges without strong latitude, local solar time, or ionospheric propagation biases would be useful in assessing the possible association of lightning with highlands or volcanos specifically. Note, however, that a surface-fixed source of "lightning," even associated with a surface feature interpreted to be volcanic, is not a guarantee that active volcanism is occurring. A correlation could emerge in another way, for example, in that atmospheric motions that manifest near the Venus cloud tops are now known to occur in a surface-fixed reference frame, due to gravity waves excited by topography (e.g., Fukuhara et al. 2017).

\section{Triboelectric discharges on Venus surface}

It is striking that on only two occasions when smallscale surface changes could have been observed on Venus, namely in the roughly $1 \mathrm{~h}$ intervals between the successive image panoramas on each of the Veneras 13 and 14 landers, sediment transport was observed on one of these (Lorenz 2016). In contrast, typically one might (depending on location) need to wait for days or months to observe surface movement on Earth; similarly, only a few surface changes were observed on Mars by the Viking landers over several years.

It has been recognized that triboelectric charging may be an important effect on Titan (Lorenz 2014; Mendez-Harper et al. 2017) as well as Mars, in environments where the lack of surface electrical conductivity via liquid water prevents rapid charge leakage. In the dry high-pressure near-surface atmosphere of Venus, it will be even harder for the charge to leak away from triboelectrically charged sediments.

It seems plausible that triboelectric charging associated with eolian sediment transport might occur on Venus; if it does, the proximity of Venus wind speeds to the transport threshold and the surface transport observation on Venera 14 may imply that it is widespread and frequent. It may not be ubiquitous, however. An obvious prerequisite is the availability of sand, dust, or gravel to be transported, and such material may be strongly supply-limited in many places (e.g., Weitz et al. 1994); although ash streaks from a number of volcanos can be recognized, the dominant source of sediment may be ejecta from the $\sim 1000$ impact craters on Venus. Topographic obstacles may play an important role in funneling winds at a regional and local scale. These caveats aside, while only a couple of sites with Magellan-resolvable sand dunes are known (e.g., Lorenz 
and Zimbelman 2014), wind streaks are found over all latitudes and longitudes.

Although we have little direct information on Venus' near-surface winds, they are unlikely to be uniformsome places will be windier than others. Notably, slope winds due to diurnal heating will be strongest on large, steep slopes at low latitudes, and an evaluation (Dobrovolskis 1993) suggested two daily peaks in speed will occur, around 0600 and $1800 \mathrm{~h}$ local solar time (upslope and downslope respectively). Since sediment transport will be favored downhill, this predicted maximum in particle motion, and thus, triboelectric charging will occur in the evening, consistent with the apparent increase in observed electrical activity then compared with early morning. It should be underscored that the high pressure at Venus' surface is a challenge to the prospect of discharges; however, in that, the breakdown field at these conditions is very high. In this respect, volcanic ash clouds may be more likely to yield discharges, since the charged dust in this case is lofted to a higher altitude where the breakdown field is lower.

\section{Conclusions and recommendations for future surveys}

This review reaches much the same conclusion as many before it, namely that more observational data are required to make a robust assessment about atmospheric electrical activity on Venus. To date, the most compelling indications of some kind of persistent atmospheric electrical activity at Venus appear to be the VLF detections by Veneras 11-14. The ELF emissions observed by Pioneer Venus, and perhaps more robustly by Venus Express, appear fully consistent with such electrical activity although they do have potential other explanations. As summarized in Table 3, rates of activity seem broadly coherent among the quite different datasets.

Of the optical observations, the ground-based observation by Hansell et al. (1995) appears the most significant in terms of robustness and area and time observed, although the very small number of flashes is challenging to interpret quantitatively. The Venera 9 observation has a number of aspects that make the interpretation difficult and suggest a possible artifact. Circumstantially, the nondetection, or at least lack of reports of detected flashes, in a number of other datasets (Pioneer Venus star tracker, VEGA, Venus Express) indicates that flashes are not a prominently observable feature of Venus, although in some cases (Pioneer Venus, VEGA), the area and/or duration of the observation is small.

It is clear that a larger area-time product, desirably with a low optical energy detection threshold, is required to assert strong upper limits on, or to obtain secure statistics of, what is likely to be a strongly spatiotemporally variable phenomenon. The present state of the art of optical detections at Venus is somewhat similar to the handful of orbits with a high detection threshold (totaling $4 \mathrm{~h}$ ), as shown in the lower panel of Fig. 11 for terrestrial data from the C/NOFS satellite-the interpretation of only a few flashes is challenging as any geographical or temporal dependence is not statistically robust. It may be hoped that the Lightning and Airglow Camera (LAC) on Akatsuki may be operated for some time, yielding statistically useful numbers of detections. The rate of optical detections for an instrument at Earth viewing from about $1000 \mathrm{~km}$ altitude, and thus viewing about 1 million $\mathrm{km}^{2}$ (e.g., FORTE, Kirkland et al. 2001) is of the order of $100-200$ per hour. The eight initial LAC observations reported by Takahashi et al. (2018) cover a few million $\mathrm{km}^{2}$ for $\sim 20 \mathrm{~min}$, and thus, many detections would have been expected if the optical flashes comparable with terrestrial ones occurred at a terrestrial rate, given a total survey of $10 \sim 20$ million $\mathrm{km}^{2}$-h. On the other hand, perhaps detectable Venus flashes may be as rare as terrestrial "superbolts" $\left(\sim 10^{9} \mathrm{~J}\right.$ optical energy). Forty such flashes were seen (Turman 1977) in 2 months of long-distance observations, i.e., full-disk $\sim 130$ million $\mathrm{km}^{2}$, from the Vela satellites. Thus, the rate of these events is $\sim 2 \times 10^{-4}$ per million $\mathrm{km}^{2}-\mathrm{h}$, and so, an instrument with observing opportunities like LAC ( $20 \mathrm{~min}$ in each 10-day orbit) is unlikely to achieve a detection, even if in operation for a decade. The subtlety of planet-averaged lightning rates not representing the highly clustered (i.e., "conditional") distribution of flashes (e.g., Fig. 4) should be noted-it is not enough to stare with a very sensitive detector at only one place if that place does not see a storm. Thus, there remains high value in obtaining further LAC observations. The question of irregular spatio-temporal sampling of an irregular spatio-temporal phenomenon such as lightning deserves further quantitative exploration, e. g., by Monte-Carlo simulations that can include, e.g., geographical, time of day, or other dependencies, but this is beyond the scope of the present review.

It may be noted that a sufficiently long optical survey may yield optical transient detections even if lightning never occurs on Venus; satellite optical observations (such as Vela, designed to detect nuclear detonations) detect flashes of large meteoroids (bolides) entering the Earth's atmosphere (Brown et al. 2002). The reported events with optical energies of the order of $4 \times 10^{9} \mathrm{~J}$ occur at a rate of $\sim 100$ /year at Earth, or about $2.5 \times 10^{-5}$ per million $\mathrm{km}^{2}-\mathrm{h}$, with less energetic events proportionately more often. Thus a $10^{6} \mathrm{~J}$ optical event might occur at $\sim 0.1$ per million $\mathrm{km}^{2}$-h, such that at least a few such events can be expected in some years of LAC observation. Note, however, that the duration of bolide entries is long compared with a lightning flash; in the Venus atmosphere, meteor "flares" are expected to last a couple of seconds (e.g., McAuliffe and Christou 2006), so 
the triggering logic of an instrument like the LAC, or the exposure time of a camera, cannot be optimal for searching for lightning and for bolides simultaneously.

The superficially bland optical appearance of Venus and its interpretation as a uniform, unchanging atmosphere has given way to a much more variable perspective revealed in the near-infrared (for example by the Akatsuki 2-micron camera-see Fig. 12); thus, it would not be surprising if the vertical motions required for charge separation were as localized as they are on Earth. Not only might the diurnal distribution of lightning production be concentrated (e.g., dusk-midnight) but there may be a geographical preference (e.g., at volcanoes or downwind of large mountainous provinces that may produce uplift in gravity waves). There may also be a meteorological influence on detection efficiency-e.g., lightning emissions may (as on Earth) be more easily detected at the edges of large convective storms, rather than at their center where the obscuring clouds may be thicker.

Above the ionosphere, surveys of whistler-mode signals from orbit have already been comparatively extensive, yielding results that remain broadly consistent from 1 year to the next, and between the Pioneer Venus and Venus Express datasets. While further observations, e.g., from a low circular orbit, would have some value in refining geographical and local time distributions, they are unlikely by themselves to be any more persuasive to the broader community, or informative on the generation mechanism. A combination of an ELF electrical/magnetic detection with another type (most obviously an optical sensor, but possibly gamma

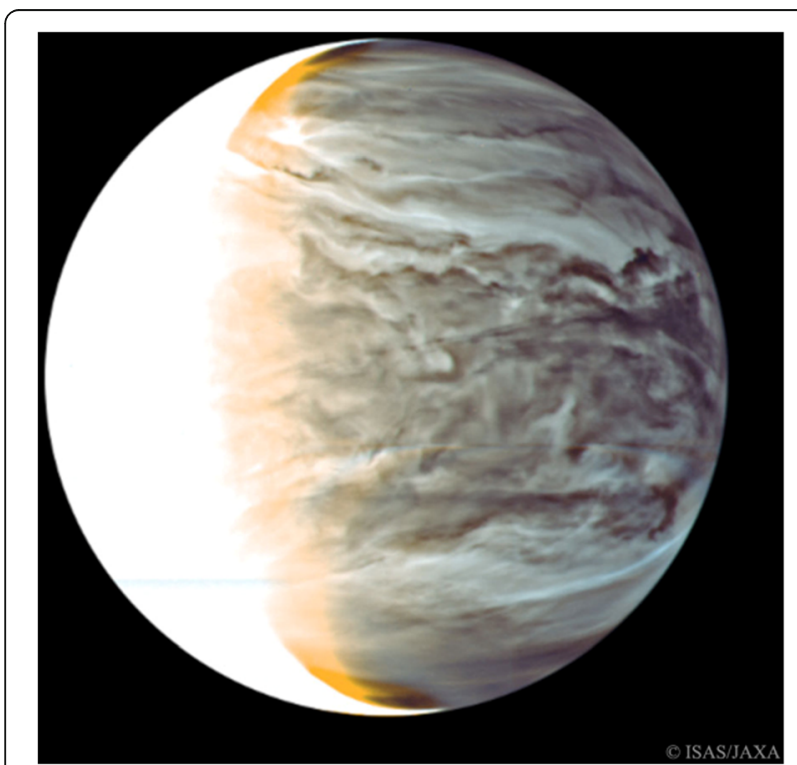

Fig. 12 The deeper view into Venus' clouds afforded by near-infrared windows (this example from the Akatsuki 2-micron camera) shows structures on a range of length scales - if lightning is associated with cloud convection as on Earth, it might be expected that lightning will be similarly patchy (see also Fig. 4) ray, or even VHF radio) would be much more compelling (as performed on FORTE and C/NOFS at Earth-see, e.g., Fig. 5) and Suszcynsky et al. 2000. As noted by Russell (2011), a low circular polar orbit is desirable for radar mapping, and a modest lightning instrument would be a valuable but relatively inexpensive augmentation to a radar mapping mission. We may note that such combined optical and RF surveys of lighting (e.g., Light et al. 2001) at Earth have been performed on a rather small satellite platform (e.g., FORTE, $210 \mathrm{~kg}$, flown in 1997).

Both the Pioneer Venus electric and the Venus Express magnetic whistler-mode observations have been made over $\sim 10$ years for each mission near periapsis ( tens of minutes during each $24 \mathrm{~h}$ orbit, or a duty cycle of $\sim 2 \%$ ). Thus, the total observing time is $\sim 0.2$ years. A radar mapper in a low circular orbit allowing continuous observation would require at least one Venus day $(\sim 0.7$ years) and probably several to sweep through the full range of longitudes and relay the data. Thus, even allowing for lightning observations only at night, piggybacking a lightning payload on a mapping mission will yield a factor of several improvements in observation duration for electromagnetic observations, with better geographical diversity, compared with prior surveys. An optical monitor on a low orbiter, with a $\sim 25 \%$ duty cycle for night-time only operation, would yield a vastly longer observation time than has been possible to date (typically a few hours).

Below the ionosphere, a long-lived (months?) aerial platform like a balloon would be useful in having a much longer observation period than a surface probe, which will be limited to a few hours. The Venera results suggest that a simple instrument like Groza or the Galileo LRD (an instrument which even with the 1980s technology had a mass of $2.5 \mathrm{~kg}$, a power demand of $3 \mathrm{~W}$ and an average data rate of only $\sim 1$ bit per second-Lanzerotti et al. 1992) would yield rich VLF data from an easily accommodated coil or loop antenna. A modern instrument, operating on a platform near the cloud tops (where temperatures and pressures are benign) could be implemented with a few hundred grams of hardware-it is basically an AM radio, and even only a week of operation would yield a dataset 100 times larger than a probe descent like Venera. Optical detection on an airborne platform would likely have a much shorter range (tens of kilometers) due to atmospheric absorption and scattering but demands so little mass or power that a flash detector should probably be included anyway. A measure of the DC electric field would also be useful to assess fair weather electricity (e.g., the character of the global electric circuit) and possible charging mechanisms; the vertical tether on a balloon is an obvious platform on which to make a simple measurement.

The incremental value of further measurements on short-lived landers or probes is not obvious, unless 
direction-finding capability (easily implemented, as in some terrestrial sensors, simply by having two coils and measuring the intensity ratio between them) is included. The crude direction-finding implemented by the single coil on the Venera probes with modest directivity coupled with somewhat uncertain spin rate information (Ksanfomality, personal communication, 2017) could not disentangle spin modulation of a finite-extent source from temporal variability in it, nor reliably isolate multiple source regions. A two-axis sensor could resolve these ambiguities, making even a single hour-long probe descent worthwhile, although a long-lived aerial platform would of course be preferable. Desirably, technology developments may eventually permit long-duration operation, and/or multiple platforms can be sent such that useful constraints on temporal or spatial variability can be determined.

Although further spacecraft measurements at Venus are sorely needed, as described above, it is likely that useful insights from ground-based observations can still be made. More sensitive optical surveys can be performed with high-speed cameras that are now readily available, and automated searches with sophisticated statistical tests have been developed (e.g., a lightning search at Jupiter by Luque et al. 2015). Additionally, lightning can be detected by radio methods (e.g., Zarka et al. 2008; Konovalenko et al. 2013) reported observations of Saturn lightning using the large UTR-2 radiotelescope at $20-25 \mathrm{MHz}$ (robust detections were made with fluxes of 100-700 Jansky). A positive simultaneous detection at Venus by both optical and radio means would be powerful evidence of lightning or related activity.

\section{Endnote}

${ }^{1}$ Note that this Taylor (Harry H., of Goddard Space Flight Center) is not the same Taylor (William W., of TRW, Inc) who authored the 1979 "discovery" paper.

\begin{abstract}
Abbreviations
C/NOFS: Communications/Navigation Outage Forecasting System (satellite); ELF: Extremely low frequency, a few $\mathrm{Hz}$ to a few hundred $\mathrm{Hz}$; FORTE: Fast On-orbit recording of Transient Events (satellite); kR: kiloRayleigh (unit of optical flux); LRD: Lightning and Radio Detector (on Galileo probe); OEFD: (Pioneer Venus) Orbiter Electric Field Detector; OGBD: (Pioneer Venus) Orbiter Gamma-Ray Detector; TGF: Terrestrial gamma-ray flash; TLE: Transient luminous event; VEx: Venus Express; VLF: Very low frequency, typically 3$100 \mathrm{kHz}$
\end{abstract}

\section{Acknowledgements \\ The author thanks Seth Hansell, Vladimir Krasnopolsky, Leonid Ksanfomality, and Don Gurnett for a candid discussion of their observations. Their acknowledgement here for responding to questions should not be taken as their endorsement of any contentions in this paper. Bob Holzworth is thanked for making C/NOFS data available and providing Fig. 4. Two anonymous referees provided constructive comments.}

\section{Funding}

RL acknowledges the support of NASA Venus Climate Orbiter Participating Scientist grant NNX16AC78G.

\section{Author's contributions}

RL conceived and designed the study and wrote the paper. The author read and approved the final manuscript.

\section{Author's information}

Ralph Lorenz is a planetary scientist on the Principal Professional Staff of the Johns Hopkins University Applied Physics Laboratory (APL). He is a member of the Cassini RADAR team, a Co-I on the Huygens Surface Science Package, a Collaborator on the InSight Seismometer team, and a NASA Participating Scientist on the JAXA Akatsuki mission. He is involved in formulating mission and instrument concepts at Titan, Europa, Venus, and Mars. He holds five NASA Group Achievement awards. He is the author of seven books, including "Dune Worlds," "Lifting Titan's Veil," "Spinning Flight," and "Space Systems Failures." Prior to joining APL in 2006, Lorenz was at the Lunar and Planetary Lab, University of Arizona. He has a B.Eng. in Aerospace Systems Engineering from the University of Southampton in the UK and a Ph.D. in Physics in 1994 from the University of Kent at Canterbury and worked for the European Space Agency on the design of the Huygens probe, for which he performed the lightning hazard assessment.

\section{Competing interests}

The authors declare that they have no competing interests.

\section{Publisher's Note}

Springer Nature remains neutral with regard to jurisdictional claims in published maps and institutional affiliations.

Received: 16 October 2017 Accepted: 4 April 2018

Published online: 20 June 2018

\section{References}

Aplin K (2013) Electrifying atmospheres: charging, ionisation and lightning in the solar system and beyond. Springer Science \& Business Media

Aplin KL, Fischer G (2017) Lightning detection in planetary atmospheres. Weather 72:46-50

Bagheri M, Dwyer JR (2016) An investigation of the possibility of detecting gamma-ray flashes originating from the atmosphere of Venus. Journal of Geophysical Research: Space Physics. 121(9):9020-9029

Bar-Nun A (1980) Production of carbon and nitrogen species by thunderstorms on Venus. Icarus 42:338-342

Barrington RE, Belrose JS (1963) Preliminary results from the very-low frequency receiver aboard Canada's Alouette satellite. Nature 198:651-656

Belton MJ, Gierasch PJ, Smith MD, Helfenstein P, Schinder PJ, Pollack JB, Rages KA, Ingersoll AP, Klaasen KP, Veverka J, Anger CD (1991) Images from Galileo of the Venus cloud deck. Science. 253(5027):1531-1536

Bondarenko NV, Head JW, Ivanov MA (2010) Present-day volcanism on Venus: evidence from microwave radiometry. Geophys Res Lett 37:L23202

Borucki WJ, Dyer JW, Phillips JR, Phan P (1991) Pioneer Venus Orbiter search for Venusian lightning. I Geophys Res 96:11033-11043

Borucki WJ, Dyer JW, Thomas GZ, Jordan JC, Comstock DA (1981) Optical search for lightning on Venus. Geophys Res Lett 8:233-236

Borucki WJ, McKay CP, Jebens D, Lakkaraju HS, Vanajakshi CT (1996) Spectral irradiance measurements of simulated lightning in planetary atmospheres. Icarus 123:336-344

Borucki WJ, McKenze RL, McKay CP, Duong ND, Boac DS (1985) Spectra of simulated lightning on Venus, Jupiter, and Titan. Icarus 64:221-232

Brown P, Spalding RE, ReVelle DO, Tagliaferri E, Worden SP (2002) The flux of small near-Earth objects colliding with the Earth. Nature 420:294-296

Bullough K, Denby M, Gibbons W, Hughes AR, Kaiser TR, Tatnall AR, Massey H, Dalziel R (1975) ELFNLF emissions observed on Ariel 4. Proc. R. Soc. Lond. A. 343(1633):207-226

Cain JC, Shapiro IR, Stolarik JD, Heppner JP (1961) A note on whistlers observed above the ionosphere. J Geophys Res 66:2677-2680

Christensen LS, Frost W, Vaughan W (1979) Proceedings of a Workshop on the Need for Lightning Observations from Space, NASA CP-2095, Huntsville

Croft TA, Price GH (1983) Evidence for a low-altitude origin of lightning on Venus. Icarus. 53(3):548-551

Daniels JTM, Russell CT, Strangeway RJ, Wei HY, Zhang TL (2012) Whistler mode bursts in the Venus ionosphere due to lightning: statistical properties using Venus Express magnetometer observations. J Geophys Res Planets 117(E4). https://doi.org/10.1029/2011JE003897 
Desch SJ, Borucki WJ, Russell CT, Bar-Nun A (2003) Progress in planetary lighting. Rep Prog Phys 65:955-997

Dobrovolskis AR (1993) Atmospheric tides on Venus. IV. Topographic winds and sediment transport. Icarus 103:276-289

Finke U (2009) Optical detection of lightning from space. In: Betz HD, Schumann $\mathrm{U}$, Laroche P (eds) Lightning: principles, instruments and applications, springer, pp 271-286

Fischer G, Kurth WS, Gurnett DA, Zarka P, Dyudina UA, Ingersoll AP, Ewald SP, Porco CC, Wesley A, Go C, Delcroix M (2011) A giant thunderstorm on Saturn. Nature 475:75-77

Fishman GJ, Bhat PN, Mallozzi R, Horack JM, Koshut T, Kouveliotou C, Pendleton GN, Meegan CA, Wilson RB, Paciesas WS, Goodman SJ, Christian HJ (1994) Discovery of intense gamma-ray flashes of atmospheric origin. Science 264: 1313-1316

Fukuhara T, Futaguchi M, Hashimoto GL, Horinouchi T, Imamura T, Iwagaimi N, Kouyama T, Murakami SY, Nakamura M, Ogohara K, Sato M (2017) Large stationary gravity wave in the atmosphere of Venus. Nat Geosci 10(2):85-88

Garcia Muñoz A, Pallé E, Rodríguez PM Cabrera-Lavers A Murgas F A multi-site ground-based search for Venus' lightning flashes, EGU General Assembly 2011, Geophysical Research Abstracts Vol. 13, EGU2011-13975, 2011

Grebowsky JM, Strangeway RJ, Hunten DM (1997) Evidence for Venus lightning. In: Venus II, pp 125-157

Gurnett DA, Kurth WS, Roux A, Gendrin R, Kennel CF, Bolton SJ (1991) Lightning and plasma wave observations from the Galileo flyby of Venus. Science:1522-1525

Gurnett DA, O'brien BJ (1964) High-latitude geophysical studies with satellite Injun 3: 5. Very-low-frequency electromagnetic radiation. Journal of Geophysical Research. 69(1):65-89

Gurnett DA, Zarka P, Manning R, Kurth WS (2001) Non-detection at Venus of high-frequency radio signals characteristic of terrestrial lightning. Nature 409(6818):313-315

Hansell SA, Wells WK, Hunten DM (1995) Optical detection of lightning on Venus. Icarus 117:345-351

Harland DM, Lorenz RD (2005) Space systems failures, springer

Hart RA, Russell CT, Leinweber H, Strangeway RJ, Zhang TL (2013) Mapping Venus lightning using ULF waves in the lower ionosphere of Venus. In: Lunar and planetary science conference, 44, abstract \# 1088

Ho CM, Strangeway RJ, Russell CT (1991) Occurrence characteristics of VLF bursts in the nightside ionosphere of Venus. Journal of Geophysical Research: Space Physics. 96(A12):21361-21369

Hueso R, Pérez-Hoyos S, Sánchez-Lavega A, Wesley A, Hall G, Go C, Tachikawa M, Aoki K, Ichimaru M, Pond JWT, Korycansky DG (2013) Impact flux on Jupiter: from superbolides to large-scale collisions. Astron Astrophys 560:A55

Huestis DL, Slanger TG (1993) New perspectives on the Venus nightglow. J Geophys Res Planets 98(E6):10839-10847

Hunten DM (1995) Venus lightning: Pros and cons. Advances in Space Research 15(4): 109-112

Imamura T, Higuchi T, Maejima Y, Takagi M, Sugimoto N, keda K, Ando H (2014) Inverse insolation dependence of Venus' cloud-level convection. Icarus 228: $181-188$

Karyagin VP, Kovtunenko VM, Kremnev RS, Kuznetsov W, Pichkhadze KM, Sklovskaia IA, Finchenko VS, laroshevskii VA (1980) Aerodynamics and dynamics of the Venera 11 and 12 descent vehicles. Cosmic Research. 17:661-669

Kirkland MW, Suszcynsky DM, Guillen JLL, Green JL (2001) Optical observations of terrestrial lightning by the FORTE photodiode detector. J Geophys Res 106: 33,499-33,509

Konovalenko AA, Kalinichenko NN, Rucker HO, Lecacheux A, Fischer G, Zarka P, Zakharenko W, Mylostna KY, Grießmeier JM, Abranin EP, Falkovich IS (2013) Earliest recorded ground-based decameter wavelength observations of Saturn's lightning during the giant E-storm detected by Cassini spacecraft in early 2006. Icarus. 224(1):14-23

Krasnopolsky V (1979) Lightning on Venus according to information obtained by the satellites Venera 9 and 10. Cosm Res 18:429-434

Krasnopolsky V (2006) A sensitive search for nitric oxide in the lower atmosphere of Venus and Mars: detection on Venus and upper limit for Mars. Icarus 192:80-91

Krasnopolsky VA (1983) Lightnings and nitric oxide on Venus. Planet Space Sci 31(11):1363-1369

Krasnopolsky VA, Krysko AA (1979) Venera 9, 10: is there a dust ring around Venus? Planet Space Sci 27(7):951-957

Ksanfomality LV, FL Scarf, WWL Taylor (1983) The electrical activity of the atmosphere of Venus, In Venus, ed. by D.M. Hunten et al. (University of Arizona Press, Tucson), pp. 565-603
Ksanfomality LV (1980) Discovery of frequent lightning discharges in clouds on Venus. Science 284:244-246

Ksanfomality LV, Vasilchikov NM, Ganpantserova OF, Petrova EV, Suvorov AP, Filippov GF, lablonskaia OV, labrova LV (1979) Electrical discharges in the atmosphere of Venus. Sov Astron Lett 5:122-126

Ksanfomality LV, Vasilchikov NM, Goroshkova NV, Petrova EV, Suvorov AP, Khondryev VK (1982) The low-frequency electromagnetic field in the Venus atmosphereevidence from VENERA-13 and VENERA-14. Sov Astron Lett 8:230-232

Lanzerotti L, Rinnert K, Dehmel G, Gliem FO, Krider EP, Uman MA, Bach J (1996) Radio frequency signals in Jupiter's atmosphere. Science 272:858-860

Lanzerotti L, Rinnert K, Dehmel G, Gliem FO, Krider EP, Uman MA, Umlauft G, Bach J (1992) The lightning and radio emission detector (LRD) instrument. Space science reviews. 60(1-4):91-109

Light TE, Suszcynsky DM, Kirkland MW, Jacobson AR (2001) Simulations of lightning optical waveforms as seen through clouds by satellites. J Geophys Res 106:17,103-17,114

Lorenz R (2018) Discharge current measurements on Venera 13 \& 14 - evidence for charged aerosols in the Venus lower atmosphere? Icarus 307:146-149

Lorenz R, Crisp D, Huber L (2018) Venus atmospheric structure and dynamics from the VEGA lander and balloons: new results and PDS archive. Icarus in press

Lorenz RD (2014) Physics of saltation and sand transport on titan: a brief review. Icarus 230:162-167

Lorenz RD (2016) Surface winds on Venus: probability distribution from in-situ measurements. Icarus 264:311-315

Lorenz RD, Lawrence DJ (2015) Gamma rays and cosmic rays at Venus: The Pioneer Venus gamma ray detector and considerations for future measurements. Planetary and Space Science. 109:129-134

Lorenz RD, Zimbelman JR (2014) Dune worlds: how windblown sand shapes planetary landscapes. Springer Science \& Business Media

Luque A, Gordillo-Vázquez FJ, Pallé E (2015) Ground-based search for lightning in Jupiter with GTC/OSIRIS fast photometry and tunable filters. Astron Astrophys 577:A94

McAuliffe JP, Christou AA (2006) Modelling meteor ablation in the venusian atmosphere. Icarus 180:8-22

Mendez-Harper J, McDonald GD, Dufek J, Malaska MJ, Burr DM, Hayes AG, McAdams J, Wray JJ (2017) Electrification of sand on titan and its influence on sediment transport. Nat Geosci 10(4):260-265

Moinelo AC, Abildgaard S, Muñoz AG, Piccioni G, Grassi D (2016) No statistical evidence of lightning in Venus night-side atmosphere from VIRTIS-Venus Express Visible observations. Icarus. 277:395-400

Nakamura M, Imamura T, Ueno M, Iwagami N, Satoh T, Watanabe $\mathrm{S}$ et al (2007) PLANET-C: Venus climate orbiter mission of Japan. Planet Space Sci 55:1831-1842

Nakamura M, Kawakatsu Y, Hirose C, Imamura T, Ishii N, Abe T, Yamazaki A, Yamada M, Ogohara K, Uemizu K, Fukuhara T (2014) Return to Venus of the Japanese Venus climate orbiter AKATSUKI. Acta Astronautica 93:384-389

Pérez-Invernón FJ, Luque A, Gordillo-Vázquez FJ (2016) Mesospheric optical signatures of possible lightning on Venus. I Geophys Res Space Physics 121(7):7026-7048

Rakov VA, Uman MA (2003) Lightning, physics and effects. Cambridge University Press

Rinnert K (1985) Lightning on other planets. Journal of Geophysical Research: Atmospheres. 90(D4):6225-6237

Rinnert K, Lanzerotti L, Uman MA, Dehmel G, Gliem FO, Krider EP, Bach J (1998) Measurements of radio frequency signals from lightning in Jupiter's atmosphere. J Geophys Res Planets 103(E10):22979-22992

Rinnert K, Lauderdale R, Lanzerotti LJ, Krider EP, Uman MA (1989) Characteristics of magnetic field pulses in earth lightning measured by the Galileo probe instrument. J Geophys Res Atmos 94(D11):13229-13235

Russell CT (1991) Venus lightning. Space Science Reviews. 55(1-4):317-356

Russell CT, Luhmann JG, Cravens TE, Nagy AF, Strangeway RJ (2007a) Venus upper atmosphere and plasma environment: critical issues for future exploration. In: Esposito LW, Stofan ER, Cravens TE (eds) Exploring Venus as a terrestrial planet, geophysical monograph 176. American Geophysical Union, Washington, DC, pp 139-156

Russell CT, Strangeway RJ, Daniels JT, Zhang TL, Wei HY (2011) Venus lightning: Comparison with terrestrial lightning. Planetary and Space Science. 59(10): 965-973

Russell CT, Zhang L, Delva M, Magnes W, Strangeway RJ, Wei HY (2008a) Lightning on Venus inferred from whistler-mode waves in the ionosphere. Nature 450:661-662 
Russell CT, Zhang TL, Strangeway RJ, Wei HY, Delva M, Magnes W (2007b) Electromagnetic waves observed by Venus express at periapsis: detection and analysis techniques. Adv Space Res 41:113-117

Russell CT, Zhang TL, Wei HY (2008b) Whistler mode waves from lightning on Venus: magnetic control of ionospheric access. I Geophys Res Planets 113(E5). https://doi.org/10.1029/2008JE003137

Sagdeev RZ, Linkin VM, Kerzhanovich W, Lipatov AN, Shurupov AA, Blamont JE, Crisp D, Ingersoll AP, Elson LS, Preston RA, Hildebrand CE, Ragent B, Seiff A, Young RE, Petit G, Boloh L, Alexandrov YN, Armand NA, Bakitko RV, Selivanov AS (1986) Overview of VEGA Venus balloon in situ meteorological measurements. Science 231:1411-1414

Sato M, Ushio T, Morimoto T, Kikuchi M, Kikuchi H, Adachi T, Suzuki M, Yamazak A, Takahashi Y, Inan U, Linscott I (2015) Overview and early results of the global lightning and sprite measurements mission. J Geophys Res Atmos 120:3822-3851. https://doi.org/10.1002/2014JD022428

Scarf FL, Jordan KF, Russell CT (1987) Distribution of whistler mode bursts at Venus. J Geophys Res Space Physics 92(A11):12407-12411

Scarf FL, Russell CT (1983) Lightning measurements from the Pioneer Venus orbiter. Geophys Res Lett 10(12):1192-1195

Scarf FL, Taylor WWL, Russell CT, Brace LH (1980) Lightning on Venus: orbiter detection of whistler signals. J Geophys Res Space Physics 85(A13):8158-8166

Seiff A, Sromovsky L, Borucki W, Craig R, Juergens D, Young RE, Ragent B (1995) Pioneer Venus 12.5 km Anomaly Workshop Report. NASA CP-3303, Moffett Field

Shalygin EV et al (2012) Search for ongoing volcanic activity on Venus: case study of Maat Mons, Sapas Mons and Ozza Mons volcanoes. Planet Space Sci 73: 294-301

Simões F, Hamelin M, Grard R, Aplin KL, Béghin C, Berthelier JJ, Besser BP, Lebreton JP, López-Moreno JJ, Molina-Cuberos GJ, Schwingenschuh K (2008) Electromagnetic wave propagation in the surface-ionosphere cavity of Venus. Journal of Geophysical Research: Planets. 113(E7):1. https://doi.org/10. 1029/2007JE003045

Sparrow JG, Ney EP (1971) Lightning observations by satellite. Nature 232:540

Suszcynsky DM, Kirkland MW, Jacobson AR, Fanz RC, Knox SO, Guillen JLL, Green JL (2000) FORTE observations of simultaneous VHF and optical emissions from lightning: basic phenomenology. J Geophys Res 105:2191-2201

Takahashi Y, M Sato, M Imai, R Lorenz, Y Yair, K Aplin, G Fischer, M Nakamura, N Ishii, T Abe, T Satoh, T Imamura, C Hirose, M Suzuki, GL Hashimoto, N Hitrata, A Yamazaki, T M Sato, M Yamada, S Murakami, Y Yamamoto, T Fukuhara, K Ogohara, H Ando, K Sugiyama, H Kashimura and S Ohtsuki (2018) Start of lightning hunting by LAC/Akatsuki, earth, planets, space, in revision

Takahashi Y, Yoshida J, Yair Y, Imamura T, Nakamura M (2008) Lightning detection by LAC onboard the Venus climate orbiter, planet-C. Space Sci Rev 137:317-334

Taylor HA Jr, Cloutier PA (1986) Venus: dead or alive? Science 234:1087-1094

Taylor W, Scarf F, Russell C, Brace L (1979) Evidence for lighting on Venus. Nature 279:614-616

Turman BN (1977) Detection of lightning superbolts. J Geophys Res 82(18):2566-2568

Turman BN (1978) Analysis of lightning data from the DMSP satellite. J Geophys Res 83:5019-5024

Van Eaton AR, Amigo Á, Bertin D, Mastin LG, Giacosa RE, González J, Valderrama O, Fontijn K, Behnke SA (2016) Volcanic lightning and plume behavior reveal evolving hazards during the April 2015 eruption of Calbuco volcano, Chile. Geophys Res Lett 43(7):3563-3571

Vorpahl JA, Sparrow LG, Ney EP (1970) Satellite observations of lightning. Science 169:860

Weitz CM, Plaut JJ, Greeley R, Saunders RS (1994) Dunes and microdunes on Venus: why were so few found in the Magellan data? Icarus 112:282-295

Williams MA, Krider EP, Hunten DM (1983) Planetary lightning: Earth, Jupiter, and Venus. Reviews of Geophysics. 21(4):892-902

Wood TG, Inan US (2002) Long-range tracking of thunderstorms using sferic measurements. J Geophys Res Atmos 107(D21). https://doi.org/10.1029/ 2001JD002008

Yair Y (2012) New results on planetary lightning. Adv Space Res 50:293-310

Zarka P, Farrell W, Fischer G, Konovalenko A (2008) Ground-based and space-based radio observations of planetary lightning. Space Sci Rev 137(1-4):257-269

\section{Submit your manuscript to a SpringerOpen ${ }^{\circ}$ journal and benefit from:}

- Convenient online submission

- Rigorous peer review

- Open access: articles freely available online

- High visibility within the field

- Retaining the copyright to your article

Submit your next manuscript at $\boldsymbol{\nabla}$ springeropen.com 